\title{
Endophytic, Non-endophytic Fungal Alkaloids and its Applications
}

\author{
Archana $\mathrm{O}^{1}$, Praveen Kumar Nagadesi ${ }^{1}$ \\ ${ }^{1}$ Department of Botany, Post Graduate and Research Center, St. Josephs College (Autonomous), Bangalore, Karnataka, India
}

DOI: $\underline{10.36348 / \text { sjpm.2022.v07i01.002 }}$ | Received: 10.12 .2021 | Accepted: 06.01 .2022 | Published: 10.01 .2022

*Corresponding author: Praveen Kumar Nagadesi

\section{Abstract}

Alkaloids are a secondary metabolite, which are extracted from a wide - array of organisms include Bacteria, Fungi, Plants and Animals. Here in present review mainly focused on the alkaloids derived from endophytic fungi and non endophytic fungi. Fungi have provided a great source of spirit for novel drug compounds as fungi derived alkaloids have done major boon to human health and well - being. In the present review listed 35 different group of alkaloids from endophytes. In which 12 different alkaloids are kept under derivatives of Indole group, 4 different alkaloids are kept under Quinoline group, 4 different alkaloids kept under amines and amide group, from non-endophytic alkaloid 27 different group of alkaloids are reported. In which 9 different type of alkaloid are mentioned under indole group of alkaloids, 4 alkaloids are reported under diketopiperazine alkaloids, 4 different alkaloids are mentioned under ergot group of alkaloids, 3 alkaloids under prenylated indole alkaloids, 3 alkaloids are mentioned under pyridine classes. The main applications of these alkaloids are antimicrobial, Antibacterial, Antifungal, Antiviral Activity Antihelmenthic, Anticancerous, Nutrient Pedaling, Photo stimulation, Endophytes in Tissue Culture Antidiabetic Activity, and Immunosuppressive Activity; hence all the alkaloids should be used as medicines in Ayurvedam. The alkaloids derived from different fungi were reviewed and their uses in medical fields were also report.

Key words: Indole Alkaloid, Endophytic alkaloid, nonendophytic alkaloid, Antiviral, Antidiabetic, Anticancerous.

Copyright $\odot \mathbf{2 0 2 2}$ The Author(s): This is an open-access article distributed under the terms of the Creative Commons Attribution 4.0 International License (CC BY-NC 4.0) which permits unrestricted use, distribution, and reproduction in any medium for non-commercial use provided the original author and source are credited.

\section{INTRODUCTION}

Now a days, a disproportion of alkaloids has been found from marine as well as in mushroom, endophytic, non - endophytic fungi in plants, which shows grade biological properties like insecticidal, cytotoxic, anticancer therapies, antifungal, antiviral activities. Alkaloids are the salient secondary metabolites. Based on the biosynthetic precursor and heterocyclic ring system, the alkaloids have been categorized into different groups which include indole, Piperidine, tropane, purine, pyrrolizidine, imidazole, quinolizidine, isoquinoline, and pyrrolidine alkaloids. Many scientists have propositioned distinct classification for alkaloids. One of the famous classifications that fractionate entire alkaloid compounds into 3 categories.

1. TRUE ALKALOIDS: these are the compounds which are acquired from an amino acid and have a heterocyclic ring with nitrogen. Example: Nicotine etc.

2. PROTO ALKALOIDS: these are the compound, which are obtained from an amino acid and possess nitrogen atom but it is not a segment of the heterocyclic ring. Example: Adrenaline etcetera.

3. PSEUDO ALKALOIDS: these are the compounds that do not derived from amino acids. Example: Caffeine etc.

Endophytic fungi are fungi that deaden indiscrete or proportion of their lifecycle colonizing interior intra cellularly inside tissues of the plants, generally do not cause any obvious symptoms of disease. These fungi can cause numerous secondary metabolites, some of these are alkaloids. The characterization of endophytic fungi is stressed as a significant position of causing for drug. Endophytic fungi generally attain nutrition or food and shelter from the host plant, reciprocated; they favor jeopardous amplified congruence to the host plants by generating some functional metabolites. Endophytic fungi inhere plant tissues without sabotaging or generating compounds that that attributable an infection to the host cell. Their coexistence means that the endophytes generate the similar or same substances to those arising from the plant. Endophytic fungi have been of immense 
Archana O \& Praveen Kumar Nagadesi; Saudi J Pathol Microbiol, Jan, 2022; 7(1): 4-19

interest from the last 20 years as potential generator of biologically active resource. They are a wealthy notch of functional secondary metabolites that contain flavonoids, terpenoids, steroids, phenol, phenylpropanoid, quinines, indole derivatives, amines, alkaloids, amides, pyrrolizidines, aliphatic isocoumarin derivatives.

Endophytes were first noted by the German Botanist Johann Henrich Friedrich Link in 1809. They were conception to be plant parasitic fungi and they were conception to be plant parasitic fungi and they were subsequent named as 'Microzymas' by French scientist Antonie. Bechamp. Endophytes may be imparted either direct from parent to progeny or among individuals. Endophytes which transmitted from parent to offspring are ordinarily literalized clonal and impart through fungal hyphae penetrating the embryo within the host's seeds, while reproduction of the fungi via asexual conidia or through sexual spore initiatives to horizontal transmission, where endophytes may propagate between plants in a population or community. Endophytes and plants apparently involve in mutualism, with endophytes, firstly aiding in the health and abidance of the host plant with subjects like pathogens and disease, water and heat stresses, nutrient accessibility and sillabub soil quality etc. In consideration, the endophytes experience carbon for energy from the plant host. Plant microbe correlations are not rigorously mutualistic as endophytic fungi can efficiently bechance pathogens or saprotrophs generally when the plant is accentuating. Endophytes may bechance operative and reproduce beneath particular environmental situations or when their host plants are pressurized or start to aging, desperately localizing the quantity of carbon provided to the endophyte.

\section{Endophytic Fungal Alkaloids}

In this review, we tried to provide an overview of the alkaloids that are derived from the different endophytic and non- endophytic fungi and potential against different diseases. And here we have mentioned 35 different groups of alkaloids. 12 different alkaloids are mentioned under derivatives of Indole group, 4 different alkaloids from Quinoline group, 4 different alkaloids from amines and amide group, 3 type of alkaloids from pyridone group, 2 different alkaloid under pyridines alkaloid, 2 alkaloids from quinazolines, 2 different alkaloids from indolizidine alkaloid group, 2 different alkaloids from spiroheterocyclic alkaloid group, 2 different alkaloids from chromone alkaloid group, 2 different alkaloids from steroidal alkaloid group, 2 alkaloids are mentioned under indole diketopiperazine alkaloids, 2 alkaloids from diketopiperazine alkaloid, 2 alkaloids from pyrrole group, 2 alkaloids from isoquinoline group, 2 alkaloid from indole - terpene alkaloid, 1 alkaloid from azaphilone alkaloid, 1 alkaloid from cinchona alkaloid group, 1 alkaloid from ergot group, 1 alkaloid from indole diterpene alkaloid, 1 alkaloid from loline group, 1 alkaloid from angularly prenylated indole alkaloid, 1 alkaloid from macfortine alkaloid, 1 alkaloid from benzophenanthridine alkaloid, 1 alkaloid from antileishmanial diketopiperazine alkaloid, 1 alkaloid from spiroquinazoline alkaloid, 1 alkaloid from flavipin derived alkaloid, 1 alkaloid from dioxopiperazine alkaloid, 1 alkaloid from dibenzo- $\alpha$-pyrone alkaloid, 1 alkaloid from prenylated indole alkaloids, 1 alkaloid from polyketide isoquinoline alkaloid, 1 alkaloid from dimeric pyrrolidine alkaloid, 1 alkaloid from sesquiterpene alkaloid, 1 alkaloid from quinazolinone alkaloid, 1 alkaloid from epipolythiodioxopiperazine group and 1 alkaloid from oxepine containing diketopiperazine type alkaloid (Table 1).

Camptothecine is a quinoline alkaloid, was produced by Fusariumsolani, Formitopsis sp. Alternaria alternata and Phomposis sp., which has great activity in the clinical use against ovarian small lung and refractory ovarian cancers and also acts as a chemotherapeutic agent in the treatment of leukemia.

Penicillium sp., have the ability to produce alkaloids such as Shearinines A, D - K, Paspalitrem A, Paspaline, Penicidones A -C, Meleagrine, Chrysogine, Chrysogenamide A, Penioxamide A, Glandicoline B, Cerevisterol, Trihistanin, Peninsulfuranols A- F, Spirotryprostatin F, most of these alkaloids exhibited antimicrobial activity and anti-malignant activities on human cancer cell lines.

Chaetomium sp., produces alkaloids such as Chaetoglobosin B - D, F, G, Chaetominine, Swainsonine, Chaetofusin A - B, Chaetoseminudin F $\mathrm{G}$, which exhibited anticancer activity on breast cancer cell lines and antimicrobial activity.

Aspergillus fumigatus sp., produces alkaloids such as Pseurotin A, Asperfumoid, Pyripyropene A and E, Chaetominine, Tryptoquivaline J exhibited antiinflammatory, immunosuppressive activities and Asperfumoid alkaloid showed Antifungal activity particularly against candida albicans.

Fusarium oxysporum produces Vinblastine and Vincristine which are used as an anticancer agent, and alkaloid Rohitukine used in chronic lymphocytic leukemia cancer treatment respectively. 
Archana O \& Praveen Kumar Nagadesi; Saudi J Pathol Microbiol, Jan, 2022; 7(1): 4-19

Table-1: Alkaloids from Endophytic fungi

\begin{tabular}{|c|c|c|c|c|c|c|}
\hline $\begin{array}{l}\text { S. } \\
\text { No }\end{array}$ & Class & $\begin{array}{l}\text { Name of } \\
\text { Alkaloid }\end{array}$ & fungal isolate & Host & Function & Reference \\
\hline 1 & $\begin{array}{l}\text { Amines and } \\
\text { amides }\end{array}$ & Phomoenamide & $\begin{array}{l}\text { Phomopis sp. } \\
\text { PUS-D15 }\end{array}$ & $\begin{array}{l}\text { Leaves of Garcinia } \\
\text { dulcis Kuiz }\end{array}$ & Antibacterial & $\begin{array}{l}\text { Zhang et al., } \\
2012\end{array}$ \\
\hline 2 & $\begin{array}{l}\text { Amines and } \\
\text { amides }\end{array}$ & p-aminoacetophenonic & Streptomyces sp. & $\begin{array}{l}\text { Mangrove } \\
\text { Aegiceras } \\
\text { cornculatum }\end{array}$ & $\begin{array}{l}\text { Pharmacological } \\
\text { activities }\end{array}$ & $\begin{array}{l}\text { Zhang et al., } \\
2012\end{array}$ \\
\hline 3 & $\begin{array}{l}\text { Amines and } \\
\text { amides }\end{array}$ & $\begin{array}{l}\text { 7-amino-4- } \\
\text { methylcoumarin }\end{array}$ & Xylaria sp. & Ginkgo biloba $\mathrm{L}$. & $\begin{array}{l}\text { Antibacterial and } \\
\text { Antifungal activities }\end{array}$ & $\begin{array}{l}\text { Zhang et al., } \\
2012\end{array}$ \\
\hline 4 & $\begin{array}{l}\text { Amines and } \\
\text { amides }\end{array}$ & Ergot & $\begin{array}{l}\text { Clavicepspurpur } \\
\text { ea } \\
\text { Clavicepssp. }\end{array}$ & $\begin{array}{l}\text { Rye, wheat and } \\
\text { Millets grains }\end{array}$ & pharmaceutical uses & $\begin{array}{l}\text { Zhang et al., } \\
2012\end{array}$ \\
\hline 5 & $\begin{array}{l}\text { Azaphilone } \\
\text { alkaloids }\end{array}$ & Chaetofusins A and B & $\begin{array}{l}\text { Chaetomium } \\
\text { fusiforme }\end{array}$ & $\begin{array}{l}\text { Liverwort Scapania } \\
\text { verrucose }\end{array}$ & Antifungal activity & $\begin{array}{l}\text { Kuklev et al., } \\
2016\end{array}$ \\
\hline 6 & $\begin{array}{l}\text { Benzophenanthri } \\
\text { dine alkaloid }\end{array}$ & Sanguinarine & $\begin{array}{l}\text { Fusarium } \\
\text { proliferatum } \\
\text { BLH51 } \\
\end{array}$ & Macleaya cordata & $\begin{array}{l}\text { Antibacterial, } \\
\text { Anthelmintic and Anti- } \\
\text { inflammatory }\end{array}$ & $\begin{array}{l}\text { Wang et al., } \\
2013\end{array}$ \\
\hline 7 & $\begin{array}{l}\text { Chromone } \\
\text { alkaloid }\end{array}$ & $\begin{array}{l}\text { Rohitukine. } \\
\text { flavopiridol }\end{array}$ & $\begin{array}{l}\text { Fusarium } \\
\text { oxysporum, } \\
\text { Fusarium solani } \\
\text { Gibberella } \\
\text { fujikuroi } \\
\end{array}$ & $\begin{array}{l}\text { Amoora rohituka, } \\
\text { Dysoxylum } \\
\text { binectariferum }\end{array}$ & $\begin{array}{l}\text { Chronic lymphocytic } \\
\text { Leukemia cancer } \\
\text { treatment, Anti - } \\
\text { inflammatory, anticancer } \\
\text { and immunotherapy. }\end{array}$ & $\begin{array}{l}\text { Kumara P. M } \\
\text { et al., } 2014\end{array}$ \\
\hline 8 & $\begin{array}{l}\text { Cinchona } \\
\text { alkaloids }\end{array}$ & $\begin{array}{l}\text { Quinine, Quinidine, } \\
\text { Cinchonidine, } \\
\text { Cinchonine }\end{array}$ & Diaporthe sp. & $\begin{array}{l}\text { Cinchona } \\
\text { ledgeriana }\end{array}$ & Antimalarial & $\begin{array}{l}\text { Maehara et } \\
\text { al., } 2012\end{array}$ \\
\hline 9 & $\begin{array}{l}\text { Dibenzo }-\alpha- \\
\text { pyrone alkaloid }\end{array}$ & Rhizovagine A & $\begin{array}{l}\text { Rhizopycnis } \\
\text { vagum Nitaf22 }\end{array}$ & Nicotiana tabacum & $\begin{array}{l}\text { Acetylcholinesterase } \\
\text { inhibitory activity }\end{array}$ & $\begin{array}{l}\text { Wang et al., } \\
2020\end{array}$ \\
\hline 10 & $\begin{array}{l}\text { Diketopiperazine } \\
\text { alkaloid }\end{array}$ & $\begin{array}{l}\text { 5S-hydroxynorvaline- } \\
\text { S-Ile }\end{array}$ & $\begin{array}{l}\text { Penicillium sp. } \\
\text { GD6 }\end{array}$ & $\begin{array}{l}\text { Chinese Mangrove } \\
\text { Bruguiera } \\
\text { gymnorrhiza }\end{array}$ & Antibacterial & $\begin{array}{l}\text { Jiang. C. S et } \\
\text { al., } 2018\end{array}$ \\
\hline 11 & $\begin{array}{l}\text { Diketopiperazine } \\
\text { alkaloid }\end{array}$ & Tryhistatin & $\begin{array}{l}\text { Penicillium sp. } \\
\text { HS-3 }\end{array}$ & $\begin{array}{l}\text { stems of Huperzia } \\
\text { serrata }\end{array}$ & Antimicrobial activity & $\begin{array}{l}\text { Shan et al., } \\
2010\end{array}$ \\
\hline 12 & $\begin{array}{l}\text { Diketopiperazine } \\
\text { alkaloids }\end{array}$ & $\begin{array}{l}\text { piperazine-2,5-dione }-1 \\
\text { and } 2\end{array}$ & Trichosporum sp. & $\begin{array}{l}\text { Seeds of Trigonella } \\
\text { foenum-graecum } \\
\text { (fabaceae) }\end{array}$ & Antileishmanial activities & $\begin{array}{l}\text { Metwaly et } \\
\text { al., } 2015\end{array}$ \\
\hline 13 & $\begin{array}{l}\text { Dimeric } \\
\text { pyrrolidine } \\
\text { alkaloid }\end{array}$ & Collacyclumines A-D & $\begin{array}{l}\text { Colletotrichum } \\
\text { salsolae } \\
\text { SCSIO41021 }\end{array}$ & Kandelia candel & Antimicrobial activity & $\begin{array}{l}\text { Lin et al., } \\
2020\end{array}$ \\
\hline 14 & $\begin{array}{l}\text { Dioxopiperazine } \\
\text { alkaloids }\end{array}$ & $\begin{array}{l}\text { Dehydrovariecolorin L } \\
\text { and dehydroechinulin }\end{array}$ & Eurotium rubrum & $\begin{array}{l}\text { Stem of mangrove } \\
\text { plant Hibiscus } \\
\text { tiliaceus }\end{array}$ & Cytotoxic effect & $\begin{array}{l}\text { Li et al., } \\
2008\end{array}$ \\
\hline 15 & $\begin{array}{l}\text { Epipolythiodioxo } \\
\text { piperazine (ETP) }\end{array}$ & Peninsulfuranols $\mathrm{A}$ - F & $\begin{array}{l}\text { Penicillium } \\
\text { janthinellum } \\
\text { HDN13-309 }\end{array}$ & $\begin{array}{l}\text { Root of Sonneratia } \\
\text { caseolaris }\end{array}$ & Cytotoxic activities & $\begin{array}{l}\text { Zhu et al., } \\
2016\end{array}$ \\
\hline 16 & Ergot alkaloids & $\begin{array}{l}\text { Fumigaclavine } \mathrm{C} \text { and } \\
\text { Pseurotin A }\end{array}$ & $\begin{array}{l}\text { Aspergillus sp. } \\
\text { EJC08 }\end{array}$ & $\begin{array}{l}\text { Bauhinia } \\
\text { guianensis } \\
\text { medicinal plant }\end{array}$ & Antibacterial & $\begin{array}{l}\text { Pinheiro et } \\
\text { al., } 2013\end{array}$ \\
\hline 17 & $\begin{array}{l}\text { Flavipin - } \\
\text { derived alkaloids }\end{array}$ & Azacoccones F-H & $\begin{array}{l}\text { Epicoccum } \\
\text { nigrum } \\
\text { MK214079 }\end{array}$ & Leaves of Salix sp. & Antibacterial activity & $\begin{array}{l}\text { Harwoko et } \\
\text { al., } 2020\end{array}$ \\
\hline 18 & $\begin{array}{l}\text { Indole - } \\
\text { diterpene } \\
\text { alkaloids }\end{array}$ & Lolitrem B & Epichole sp & Rye grass & Toxicity in insects & $\begin{array}{l}\text { Philippe, } \\
2016\end{array}$ \\
\hline 19 & Indole alkaloid & Glandicoline B, & Penicillium $\mathrm{sp}$ & $\begin{array}{l}\text { Roots of Mauritia } \\
\text { flexuosa }\end{array}$ & Antimicrobial activity & $\begin{array}{l}\text { Koolen } \text { et al., } \\
2012\end{array}$ \\
\hline 20 & Indole alkaloid & Piperine & Periconia $\mathrm{sp}$. & Piper longum & Antituberculosis activity & $\begin{array}{l}\text { Verma et al., } \\
2011\end{array}$ \\
\hline 21 & Indole alkaloids & Vincamine & Geomyces sp & Nerium indicum & $\begin{array}{l}\text { Nootropic drugs - } \\
\text { Cerebral insufficiencies } \\
\text { treatment }\end{array}$ & $\begin{array}{l}\text { Na et al., } \\
2016\end{array}$ \\
\hline 22 & Indole alkaloids & $\begin{array}{l}\text { Vinblastine and } \\
\text { vincristine }\end{array}$ & $\begin{array}{l}\text { Fusarium solani, } \\
\text { Fusarium } \\
\text { oxysporum }\end{array}$ & $\begin{array}{l}\text { Catharanthus } \\
\text { roseus }\end{array}$ & Anticancer agents & $\begin{array}{l}\text { Kumar et al., } \\
2013\end{array}$ \\
\hline 23 & Indole alkaloids & $\begin{array}{l}\text { Fumitremorgin B and } \\
\text { C }\end{array}$ & $\begin{array}{l}\text { Alternaria sp. } \\
\text { FL25 }\end{array}$ & Ficus carica & Anticancerous activity & $\begin{array}{l}\text { Feng et al., } \\
2010\end{array}$ \\
\hline 24 & Indole alkaloids & Cristatumins A-D & $\begin{array}{l}\text { Eurotium } \\
\text { cristatum } \text { EN- } \\
220 \\
\end{array}$ & $\begin{array}{l}\text { Marine alga } \\
\text { Sargassum } \\
\text { thunbergii }\end{array}$ & $\begin{array}{l}\text { Antibacterial activity } \\
\text { Cristatumins D showed } \\
\text { average lethal activity }\end{array}$ & $\begin{array}{l}\text { Du et al., } \\
2012\end{array}$ \\
\hline
\end{tabular}


Archana O \& Praveen Kumar Nagadesi; Saudi J Pathol Microbiol, Jan, 2022; 7(1): 4-19

\begin{tabular}{|c|c|c|c|c|c|c|}
\hline & & & & & toward brine shrimp & \\
\hline 25 & Indole alkaloids & $\begin{array}{l}\text { Chetoseminudin F and } \\
\text { G }\end{array}$ & $\begin{array}{l}\text { Chaetomium } \\
\text { sp.SYP-F7950 }\end{array}$ & Panax notoginseng & Antibacterial activity & $\begin{array}{l}\text { Peng et al., } \\
2019\end{array}$ \\
\hline 26 & $\begin{array}{l}\text { Indole } \\
\text { derivatives }\end{array}$ & $\begin{array}{l}\text { Chaetoglobosin B-D, } \\
\text { F-G }\end{array}$ & $\begin{array}{l}\text { Chaetomium } \\
\text { elatum }\end{array}$ & Isolated from soil & Anticancer agents & $\begin{array}{l}\text { Zhang et al., } \\
2012\end{array}$ \\
\hline 27 & $\begin{array}{l}\text { Indole } \\
\text { derivatives }\end{array}$ & $\begin{array}{l}\text { Shearinines A, } \\
\mathrm{D}-\mathrm{K}, \\
\text { Paspalitrem A } \\
\text { And paspaline }\end{array}$ & Penicillium sp. & $\begin{array}{l}\text { Aegiceras } \\
\text { corniculatum }\end{array}$ & $\begin{array}{l}\text { Showed blocking activity } \\
\text { on large conductance } \\
\text { calcium - activated } \\
\text { potassium channels in } \\
\text { vitro }\end{array}$ & $\begin{array}{l}\text { Zhang et al., } \\
2012\end{array}$ \\
\hline 28 & $\begin{array}{l}\text { Indole } \\
\text { diketopiperazine } \\
\text { alkaloids }\end{array}$ & Isovariecolorin 1 & $\begin{array}{l}\text { Eurotium } \\
\text { cristatum } \text { EN- } \\
220\end{array}$ & $\begin{array}{l}\text { Marine alga } \\
\text { Sargassum thunbe }\end{array}$ & $\begin{array}{l}\text { Exhibited antioxidative } \\
\text { activities and showed } \\
\text { lethal activity against } \\
\text { brine shrimp }\end{array}$ & $\begin{array}{l}\text { Du et al., } \\
2017\end{array}$ \\
\hline 29 & $\begin{array}{l}\text { Indole- } \\
\text { diketopiperazine }\end{array}$ & Spirotryprostatin F & $\begin{array}{l}\text { Penicillium } \\
\text { brefeldianum }\end{array}$ & Solid cultures & $\begin{array}{l}\text { Showed cytotoxic effects } \\
\text { toward HepG2 and MDA } \\
\text { - MB - 231 cells with } \\
\text { inhibition concentration } \\
\text { (IC50) values of } \\
14.1 \mu \mathrm{mol} / \mathrm{L} \text { and } \\
35.5 \mu \mathrm{mol} / \mathrm{L}\end{array}$ & $\begin{array}{l}\text { Gao et al., } \\
2017\end{array}$ \\
\hline 30 & $\begin{array}{l}\text { Indolizidine } \\
\text { alkaloids }\end{array}$ & Swainsonine & Chaetomium sp. & $\begin{array}{l}\text { Swainsona } \\
\text { canescens } \\
\end{array}$ & $\begin{array}{l}\text { An } \alpha \text {-mannosidase and } \\
\text { mannosidase ii }\end{array}$ & $\begin{array}{l}\text { Grum et al., } \\
2013\end{array}$ \\
\hline 31 & $\begin{array}{l}\text { Indolizidine } \\
\text { alkaloids }\end{array}$ & Swainsonine & $\begin{array}{l}\text { Alternaria } \\
\text { oxytropis }\end{array}$ & $\begin{array}{l}\text { Astralagus and } \\
\text { oxytropis genera }\end{array}$ & $\begin{array}{l}\text { As a Selective inhibitor } \\
\text { of both lysosomal acid } \\
\text { and cytosolic } \alpha- \\
\text { mannosidase ii }\end{array}$ & $\begin{array}{l}\text { Song et al., } \\
2019 \text {, Cook } \\
\text { et al., 2014, }\end{array}$ \\
\hline 32 & $\begin{array}{l}\text { Indolosesquiterp } \\
\text { enoid alkaloids }\end{array}$ & $\begin{array}{l}\text { Mycoleptodiscins A } \\
\text { and B }\end{array}$ & $\begin{array}{l}\text { Mycoleptodiscus } \\
\text { sp. }\end{array}$ & $\begin{array}{l}\text { Desmotes } \\
\text { incomparabilis in } \\
\text { Panama }\end{array}$ & Anticancer agent & $\begin{array}{l}\text { Ortega et al., } \\
2013\end{array}$ \\
\hline 33 & $\begin{array}{l}\text { Isoquinolone } \\
\text { alkaloid }\end{array}$ & $\begin{array}{l}\text { 5-hydroxy-8-methoxy- } \\
\text { 4-phenylisoquinolin - } 1 \\
(2 \mathrm{H}) \text {-one, } 3 \text {-O- } \\
\text { methylviridicatin and } \\
\text { viridicatol }\end{array}$ & $\begin{array}{l}\text { Penicillium sp. } \\
\text { R22 }\end{array}$ & Nerium indicum & $\begin{array}{l}\text { All three showed } \\
\text { antifungal activities and } \\
\text { viridicatol showed } \\
\text { antibacterial activity } \\
\text { toward staphylococcus } \\
\text { aureus with minimum } \\
\text { inhibitory concentration } \\
\text { (MIC) value of } 15.6 \mu \mathrm{g} / \mathrm{mL}\end{array}$ & $\begin{array}{l}\text { Ma et al., } \\
2017\end{array}$ \\
\hline 34 & Loline alkaloids & Amino pyrrolizidines & $\begin{array}{l}\text { Neotyphodium } \\
\text { uncinatum }\end{array}$ & $\begin{array}{l}\text { Meadow fescue } \\
\text { grass }\end{array}$ & $\begin{array}{l}\text { Defense mechanism } \\
\text { toward insect herbivores }\end{array}$ & $\begin{array}{l}\text { Blankenship } \\
\text { et al., } 2001\end{array}$ \\
\hline 35 & $\begin{array}{l}\text { Macfortine group } \\
\text { of alkaloids }\end{array}$ & Chrysogenamide A & $\begin{array}{l}\text { Penicillium } \\
\text { chrysogenum }\end{array}$ & $\begin{array}{l}\text { Cistanche } \\
\text { deserticola Y.C. } \\
\text { Ma }\end{array}$ & $\begin{array}{l}\text { Showed a neurocyte } \\
\text { protection effect toward } \\
\text { oxidative stress - induced } \\
\text { cell death in SH-SY5Y } \\
\text { cells }\end{array}$ & $\begin{array}{l}\text { Lin et al., } \\
2008\end{array}$ \\
\hline 36 & $\begin{array}{l}\text { Meleagrine } \\
\text { alkaloid }\end{array}$ & $\begin{array}{l}\text { Meleagrine and } \\
\text { chrysogine }\end{array}$ & Penicillium $\mathrm{sp}$. & $\begin{array}{l}\text { Annona squamosa } \\
L .\end{array}$ & $\begin{array}{l}\text { Meleagrine alkaloid } \\
\text { exhibited inhibitory } \\
\text { activities toward } \\
\text { leukemia }\end{array}$ & $\begin{array}{l}\text { Yunianto et } \\
\text { al., } 2014\end{array}$ \\
\hline 37 & $\begin{array}{l}\text { Mycoleptodiscin } \\
\text { alkaloids }\end{array}$ & Mycoleptodiscin B & $\begin{array}{l}\text { Mycoleptodiscus } \\
\text { sp. }\end{array}$ & $\begin{array}{l}\text { Calamus thwaitesii } \\
\text { Becc }\end{array}$ & Antimicrobial activity & $\begin{array}{l}\text { Dissanayake, } \\
\text { et al., } 2016\end{array}$ \\
\hline 38 & $\begin{array}{l}\text { Oxepine } \\
\text { containing } \\
\text { diketopiperazine } \\
\text { type alkaloids } \\
\end{array}$ & Varioloids A and B & $\begin{array}{l}\text { Paecilomyces } \\
\text { variotii } \mathrm{EN}-291\end{array}$ & Algal derived & $\begin{array}{l}\text { Displayed potent activity } \\
\text { toward the plant } \\
\text { pathogenic fungus } \\
\text { Fusarium graminearum }\end{array}$ & $\begin{array}{l}\text { Zhang et al., } \\
2015\end{array}$ \\
\hline 39 & $\begin{array}{l}\text { Polyketide } \\
\text { isoquinoline } \\
\text { alkaloid }\end{array}$ & Fusarimine & $\begin{array}{l}\text { Fusarium sp. } \\
\text { LN12 }\end{array}$ & Melia azedarach & Antibacterial activity & $\begin{array}{l}\text { Yang et al., } \\
2012\end{array}$ \\
\hline 40 & $\begin{array}{l}\text { Prenylated indole } \\
\text { alkaloid }\end{array}$ & $\begin{array}{l}\text { Penioxamide A and 18- } \\
\text { hydroxydecaturin B }\end{array}$ & $\begin{array}{l}\text { Penicillium } \\
\text { oxalicum EN - } \\
201\end{array}$ & $\begin{array}{l}\text { From the Leaves of } \\
\text { Rhizophora stylosa }\end{array}$ & $\begin{array}{l}\text { Exhibited potent brine } \\
\text { shrimp lethality with } \\
\text { lethal dose (LD50) } \\
\text { values of } 5.6 \text { and } 2,3 \mu \mathrm{M} \\
\text { respectively. }\end{array}$ & $\begin{array}{l}\text { Zhang et al., } \\
2015\end{array}$ \\
\hline 41 & $\begin{array}{l}\text { Prenylated indole } \\
\text { alkaloids }\end{array}$ & $\begin{array}{l}\text { Amoenamide } \mathrm{C} \text { and } \\
\text { Sclerotiamide B }\end{array}$ & $\begin{array}{l}\text { Fusarium } \\
\text { sambucinum }\end{array}$ & Nicotiana tabacum & Insecticidal activities & $\begin{array}{l}\text { Zhang et al., } \\
2019\end{array}$ \\
\hline 42 & $\begin{array}{l}\text { Protoberberine } \\
\text { alkaloid }\end{array}$ & $\begin{array}{l}\text { Palmatine } 7-\mathrm{N}- \\
\text { oxide }\end{array}$ & $\begin{array}{l}\text { Coelomycetes } \\
\text { AFKR - } 3\end{array}$ & $\begin{array}{l}\text { Young stems of } \\
\text { yellow moon shed } \\
\text { plant, } \\
\text { Archangelisia flava } \\
\text { (L.) Merr. }\end{array}$ & $\begin{array}{l}\text { Antimicrobial activity } \\
\text { toward pathogenic } \\
\text { bacteria and fungi }\end{array}$ & $\begin{array}{l}\text { Agusta } \text { et al., } \\
2014\end{array}$ \\
\hline
\end{tabular}


Archana O \& Praveen Kumar Nagadesi; Saudi J Pathol Microbiol, Jan, 2022; 7(1): 4-19

\begin{tabular}{|c|c|c|c|c|c|c|}
\hline 43 & Pyridine alkaloid & $\begin{array}{l}\text { Pyripyropene } \mathrm{A} \text { and } \mathrm{E} \text {, } \\
1,11 \text {-dideacetyl- } \\
\text { pyripyropene } \mathrm{A}, \\
\text { Chaetominine, } \\
\text { Tryptoquivaline } \mathrm{J} \text {, } \\
\text { Fumitremorgin } \mathrm{C}, 1 \text { - } \\
\text { acetyl- } \beta \text {-carboline and } \\
\text { nicotinic acid }\end{array}$ & $\begin{array}{l}\text { Aspergillus } \\
\text { fumigatus } \\
\text { HQD24 }\end{array}$ & $\begin{array}{l}\text { Chinese mangrove } \\
\text { plant Rhizophora } \\
\text { mucronate }\end{array}$ & $\begin{array}{l}\text { They exhibited } \\
\text { immunosuppressive and } \\
\text { cytotoxic activities }\end{array}$ & $\begin{array}{l}\text { Zou et al., } \\
2021\end{array}$ \\
\hline 44 & Pyridines & $\begin{array}{l}\text { Penicidones } \\
\text { A-C }\end{array}$ & Penicillium sp. & $\begin{array}{l}\text { Stem of Quercus } \\
\text { variabilis }\end{array}$ & $\begin{array}{l}\text { Anticancer agent Showed } \\
\text { moderate cytotoxicity on } \\
\text { human cancer cell lines }\end{array}$ & $\begin{array}{l}\text { Zhang et al., } \\
2012\end{array}$ \\
\hline 45 & $\begin{array}{l}\text { Pyridone } \\
\text { alkaloid }\end{array}$ & Campyridones A-D & $\begin{array}{l}\text { Campylocarpon } \\
\text { sp. HDN13-307 }\end{array}$ & $\begin{array}{l}\text { From the Roots of } \\
\text { mangrove plant, } \\
\text { Sonneratia } \\
\text { caseolaris }\end{array}$ & $\begin{array}{l}\text { Exhibited cytotoxic } \\
\text { activity toward P388 } \\
\text { cells }\end{array}$ & $\begin{array}{l}\text { Zhu et al., } \\
2016\end{array}$ \\
\hline 46 & $\begin{array}{l}\text { Pyridone } \\
\text { alkaloids }\end{array}$ & Fusapyridons A and B & $\begin{array}{l}\text { Fusarium sp. YG } \\
-45\end{array}$ & Maackia chinensis & $\begin{array}{l}\text { Displayed antimicrobial } \\
\text { activity toward } \\
\text { Pseudomonas aeruginosa } \\
\text { and staphylococcus } \\
\text { aureus }\end{array}$ & $\begin{array}{l}\text { Tsuchinari et } \\
\text { al., } 2007\end{array}$ \\
\hline 47 & $\begin{array}{l}\text { Pyridone } \\
\text { alkaloids }\end{array}$ & Tolypyridone A & $\begin{array}{l}\text { Tolypocladium } \\
\text { cylindrosporum } \\
\text { (endolichen } \\
\text { fungus) } \\
\end{array}$ & $\begin{array}{l}\text { Lethariella } \\
\text { zahlbruckneri }\end{array}$ & $\begin{array}{l}\text { Cytotoxic effects on } \\
\text { human tumor cells }\end{array}$ & $\begin{array}{l}\text { Li et al., } \\
2015\end{array}$ \\
\hline 48 & Pyrrole alkaloid & $\begin{array}{l}\mathrm{N} \text {-[4-(2-formyl-5- } \\
\text { hydroxymethyl-pyrrol- } \\
\text { 1-yl)-butyl]-acetamide }\end{array}$ & $\begin{array}{l}\text { Fusarium } \\
\text { incarnatum } \\
\text { (HKI00504) }\end{array}$ & $\begin{array}{l}\text { Aegiceras } \\
\text { corniculatum }\end{array}$ & Cytotoxic activities & $\begin{array}{l}\text { Li } \text { et al., } \\
2008\end{array}$ \\
\hline 49 & $\begin{array}{l}\text { Pyrrolidones } \\
\text { alkaloids }\end{array}$ & $\begin{array}{l}\text { Phomapyrrolidones A- } \\
\text { C }\end{array}$ & Phoma sp. & $\begin{array}{l}\text { Saurauia } \\
\text { scaberrinae }\end{array}$ & $\begin{array}{l}\text { Showed poor } \\
\text { antitubercular activity at } \\
\text { subcytotoxic } \\
\text { concentrations }\end{array}$ & $\begin{array}{l}\text { Wijeratne } e t \\
\text { al., } 2013\end{array}$ \\
\hline 50 & $\begin{array}{l}\text { Quinazoline } \\
\text { alkaloid }\end{array}$ & $\begin{array}{l}\text { (1R,4R)-1,4-(2,3)- } \\
\text { indolmethane-1- } \\
\text { methyl-2,4-dihydro- } \\
\text { 1H-pyrazino-[2,1-b]- } \\
\text { quinazoline-3,6-dione }\end{array}$ & $\begin{array}{l}\text { Penicillium } \\
\text { vinaceum }\end{array}$ & Crocus sativus & Antifungal agent & $\begin{array}{l}\text { Zheng et al., } \\
2011\end{array}$ \\
\hline 51 & Quinazolines & Chaetominine & Chaetomium sp. & $\begin{array}{l}\text { Adenophora } \\
\text { axilliflora leaves }\end{array}$ & $\begin{array}{l}\text { Anticancer agent } \\
\text { Exhibited high } \\
\text { cytotoxicity toward } \\
\text { human leukemia K562 }\end{array}$ & $\begin{array}{l}\text { Zhang et al., } \\
2012\end{array}$ \\
\hline 52 & $\begin{array}{l}\text { Quinazolinone } \\
\text { alkaloids }\end{array}$ & Aniquinazolines A-D & $\begin{array}{l}\text { Aspergillus } \\
\text { nidulans }\end{array}$ & Rhizophora stylosa & $\begin{array}{l}\text { Showed antibacterial and } \\
\text { cytotoxic activity }\end{array}$ & $\begin{array}{l}\text { An, et al., } \\
2013\end{array}$ \\
\hline 53 & Quinoline & Camptothecine (CPT) & $\begin{array}{l}\text { Fusarium solani, } \\
\text { Fomitopsis } \mathrm{sp} ., \\
\text { Alternaria } \\
\text { alternata } \text { and } \\
\text { Phomposis } \mathrm{sp} .\end{array}$ & $\begin{array}{l}\text { Nethapodytes } \\
\text { fortida(grass), } \\
\text { andMiquelia } \\
\text { dentata Bedd }\end{array}$ & $\begin{array}{l}\text { As a chemotherapeutic } \\
\text { agent in the treatment of } \\
\text { leukemia and clinical use } \\
\text { toward ovarian, small } \\
\text { lung and refractory } \\
\text { ovarian cancers }\end{array}$ & $\begin{array}{l}\text { Zhang } \text { et al., } \\
\text { 2012, } \\
\text { Pund, Joshi } \\
2017 \text { and } \\
\text { Shweta } \text { et al., } \\
2013\end{array}$ \\
\hline 54 & Quinoline & Aspernigerin & Aspergillus niger & $\begin{array}{l}\text { Cynodon dactylon } \\
\text { (plant) }\end{array}$ & $\begin{array}{l}\text { Cytotoxic potential to the } \\
\text { cancer cell lines } \\
\text { nasopharyngeal } \\
\text { epidermoid KB with } \\
\text { inhibition concentration } \\
\text { value (IC50) } 22 \mu \mathrm{g}\end{array}$ & $\begin{array}{l}\text { Zhang et al., } \\
2012\end{array}$ \\
\hline 55 & Quinoline & Penicinoline & $\begin{array}{l}\text { endophytic } \\
\text { fungusPenicilliu } \\
m \mathrm{sp} .\end{array}$ & Mangrove & $\begin{array}{l}\text { Showed cytotoxicity } \\
\text { against } 95-\mathrm{D} \text { and } \\
\text { HepG2 cell lines with IC } \\
\text { values } 0.57 \mu \mathrm{g} / \mathrm{mL} \text { and } \\
6.5 \mu \mathrm{g} / \mathrm{mL}\end{array}$ & $\begin{array}{l}\text { Zhang et al., } \\
2012\end{array}$ \\
\hline 56 & $\begin{array}{l}\text { Quinoline and } \\
\text { iso quinoline }\end{array}$ & Asperfumoid & $\begin{array}{l}\text { Aspergillus } \\
\text { fumigatus } \\
\text { CY018 }\end{array}$ & $\begin{array}{l}\text { Cynodon dactylon } \\
\text { (plant) }\end{array}$ & $\begin{array}{l}\text { Antifungal, has specific } \\
\text { activity toward Candida } \\
\text { albicans }\end{array}$ & $\begin{array}{l}\text { Zhang et al., } \\
2012\end{array}$ \\
\hline 57 & $\begin{array}{l}\text { Sesquiterpene } \\
\text { alkaloids }\end{array}$ & Huperzine A & $\begin{array}{l}\text { Paecilomyces } \\
\text { tenuis } \text { YS-13 }\end{array}$ & Huperzia serrata & $\begin{array}{l}\text { Acts as a cholinesterase } \\
\text { inhibitor and improves } \\
\text { neurotransmitters in the } \\
\text { brain }\end{array}$ & $\begin{array}{l}\text { Su et al., } \\
2014\end{array}$ \\
\hline 58 & $\begin{array}{l}\text { Spiro- } \\
\text { heterocyclic } \\
\text { alkaloid }\end{array}$ & 3'S- pestaloamide A & Pestalotiopsis sp. & Isodon xerophilus & $\begin{array}{l}\text { Exhibited the latent } \\
\text { cancer immunotherapy } \\
\text { activities }\end{array}$ & $\begin{array}{l}\text { Daley et al., } \\
2021\end{array}$ \\
\hline
\end{tabular}


Archana O \& Praveen Kumar Nagadesi; Saudi J Pathol Microbiol, Jan, 2022; 7(1): 4-19

\begin{tabular}{|c|c|c|c|c|c|c|}
\hline 59 & $\begin{array}{l}\text { Spiro- } \\
\text { heterocyclic } \gamma- \\
\text { lactam alkaloid }\end{array}$ & Pseurotin A & $\begin{array}{l}\text { Aspergillus } \\
\text { fumigatus }\end{array}$ & $\begin{array}{l}\text { stem of } \\
\text { Erythrophleum } \\
\text { fordii olive }\end{array}$ & $\begin{array}{l}\text { Which performed } \\
\text { indirect anti - } \\
\text { inflammatory activity } \\
\text { with inhibition } \\
\text { concentration (IC50) } \\
\text { value of } 5.20 \mu \mathrm{M}\end{array}$ & $\begin{array}{l}\text { Hawary et } \\
\text { al., } 2020\end{array}$ \\
\hline 60 & $\begin{array}{l}\text { Spiroquinazoline } \\
\text { alkaloids }\end{array}$ & $\begin{array}{l}\text { Alanditrypinone, } \\
\text { alantryphenone, } \\
\text { alantrypinene and } \\
\text { alantryleunone } \\
\end{array}$ & Eupenicillium sp. & Murraya paniculate & Medicinal use & $\begin{array}{l}\text { Barros et al., } \\
2005\end{array}$ \\
\hline 61 & $\begin{array}{l}\text { Steroidal } \\
\text { alkaloid }\end{array}$ & $\begin{array}{l}\text { Peimisine and } \\
\text { imperialine-3 } \beta \text {-D- } \\
\text { glucoside }\end{array}$ & $\begin{array}{l}\text { Fusarium } \\
\text { redolens } 6 \mathrm{WBY} 3\end{array}$ & $\begin{array}{l}\text { Fritillaria } \\
\text { unibracteata var. } \\
\text { wabuensis }\end{array}$ & $\begin{array}{l}\text { Immunosuppresive and } \\
\text { hepatoprotective agents }\end{array}$ & $\begin{array}{l}\text { pan et al., } \\
2015\end{array}$ \\
\hline 62 & $\begin{array}{l}\text { Steroidal } \\
\text { alkaloids }\end{array}$ & $\begin{array}{l}\text { Peimisine and } \\
\text { Peiminine alkaloids }\end{array}$ & Fusarium sp. & $\begin{array}{l}\text { Fritillaria } \\
\text { Unibracteata } \\
\text { var.wabensis }\end{array}$ & $\begin{array}{l}\text { Has a various } \\
\text { toxicological and } \\
\text { pharmacological effects } \\
\text { on humans }\end{array}$ & $\begin{array}{l}\text { pan et al., } \\
2014\end{array}$ \\
\hline 63 & $\begin{array}{l}\text { Terpenoid indole } \\
\text { alkaloids }\end{array}$ & $\begin{array}{l}\text { Vincristine and } \\
\text { Vinblastine }\end{array}$ & $\begin{array}{l}\text { Talaromyces } \\
\text { radicus }\end{array}$ & $\begin{array}{l}\text { Catharanthus } \\
\text { roseus }\end{array}$ & $\begin{array}{l}\text { Which induce Apoptotic } \\
\text { cell death }\end{array}$ & $\begin{array}{l}\text { Palem } \text { et al., } \\
2015\end{array}$ \\
\hline
\end{tabular}

\section{Non-Endophytes}

Saprophytes are also known as Saprotroph or saprobe, organism that feeds on nonliving organic substance called as detritus at an infinitesimal stage. The etymology of the term saprotroph comes from the Greek word 'Sapros' means rotten and term 'trophe' means nourishment. Saprophytic organisms are contemplated endangerment to decomposition and nutrient cycling and inhere fungi, some bacteria and also fungus like organisms called as water molds. Saprophytic fungi are the broadest swarm of fungi, which are accountable for digesting and reprocessing dead plant and animal substances. These are the fruit bodies we can see on dead trees, leaf pieces, even on excrement. Saprotrophs feed by a method called as absorptive nutrition. In which nutritional substance such as dead organism or other non - living organic substance. Saprophytes directly breakdown by a different type of enzymes that are produced by the saprotroph. The enzymes coder the detritus into candid forms, which are then absorbed by the cells to nourish the organism. Enzymes play major role in decreasing the assemblage of dead organic substances and in reprocessing needful nutrients, specifically Carbon and Nitrogen Fungi that disincorporate leaves and twigs in organic trash, which are present on the forest floor, inhere, Marasmius and many other species. Some fungi; for example, Pilobolus, feed mainly on the herbivores dung. Wood carrion fungi, including turkey Tails, Pleurotus and Ganoderma sp. saprophytic fungi can also show negative commercial impacts to the wood industry, dis-incorporate both cut timber and dead rind of living trees. Damnum to houses from 'dry rot' is affected by the wood - spoil species Serpula lacrymans.

Parasitic and pathogenic fungi conform symbiotic association with other living organisms, likewise to mycorrhizal fungi; still they welfare to the damnum of their host. Several lacerate acts on trees and other plants, and also attacks mushroom and occasionally portrayal the host species unidentifiable. Though animal kingdom members are incurring to parasitic fungal infection. Parasitic fungi can be an unbelievably ruinous force, occasionally afflict commercial logging action and forest administration attempts. At Mount rainer, white pine blister, a fungal disease caused by Cronartium ribicola frightens more Heave white bark pine. White pine blister rust was initiated to North America in the early $20^{\text {th }}$ century. It affects branch swelling, branch death, and blights from which orange vesicle appear. Anyways affected trees generally die, occasionally within a few years of infection. Significantly, this fungus depends on two unlike varieties of hosts to full fill its life cycle. Spores sorted by affected white bark pine trees do not go on to affect other trees. In lieu, they infect smaller plants for examples, Gooseberry, Currant and also Indian paintbrush. Parasitic fungi are coming in close connection with their host plants, with the help of motile zoospores; this can break down the cytoplasm from where they will colonize the entire plant.

\section{Nonendophytic Fungal Alkaloids}

Not only endophytic fungi have future and feature in the synthesis of secondary metabolites particularly alkaloids, but we can also extract alkaloids from non - endophytic fungi. These alkaloids have proven themselves their requirements in pharmacological activities, not only in medicinal field but also in the agricultural field. Under non-endophytic alkaloid we have reported 27 different group of alkaloids. 9 different type of alkaloid are mentioned under indole group of alkaloids, 4 alkaloids are reported under diketopiperazine alkaloids, 4 different alkaloids are mentioned under ergot group of alkaloids, 3 alkaloids under prenylated indole alkaloids, 3 alkaloids are mentioned under pyridone, 2 alkaloids under benzodiazepine alkaloids, 2 alkaloids under quinazoline, 2 alkaloids under sesquiterpene alkaloid, 2 alkaloids under indole diketopiperazine alkaloids, 2 alkaloids are reported under clavine, 1 alkaloid under pyridone, 1 alkaloid under isoquinolone, 1 alkaloid under imidazolone, 1 alkaloid under peptide ergot, 1 alkaloid under pyrrole based dimeric alkaloid, 1 alkaloid under pyrrole - imidazole, 2 alkaloid under 
spiroindolinone alkaloids, 1 alkaloid under azaphilone, 1 alkaloid under indole based cytochalasin alkaloid, 1 alkaloid under tyrosine, 1 alkaloid under isoechinuline type, 1 alkaloid under diasteromeric quinolinone alkaloids, 1 alkaloid under piperazine, 1 alkaloid is mentioned under dioxopiperazine alkaloids, 1 alkaloid under pentacyclic alkaloid, 1 alkaloid under mixture of quaternary alkaloids, 1 alkaloids under pyrrolidine and 1 alkaloid under epipolythiodioxopiperazine (Table 2).

Claviceps species produces alkaloids such as Clavine, Elymoclavine - $\mathrm{O}-\beta-\mathrm{D}-$ fructoside, $\gamma-$ ergokryptinine, these alkaloids showed their activities in the production of antimigraine drugs, uterotonics, and also as prolactin inhibitor, antiparkinson agent and pain releivers.

Chaetomium globosum produces alkaloids such as Chaetoglobinol A, Chaetocochin J exhibited antibacterial activity particularly against Bacillus subtilis, and Armochaeglobines A and B alkaloid showed anticancer activities on human cancer cell lines.

Aspergillus ochraceus produces alkaloids such as Circumdatin A - C, Spermides A, used for gastrointestinal and central nervous system disorders and displayed average inhibition activity against Pseudomonas aeruginosa with a minimum inhibition concentration (MIC) value of $0.8 \mu \mathrm{M}$ respectively.

Table-2: Alkaloids from Non endophytic fungi

\begin{tabular}{|c|c|c|c|c|c|c|}
\hline $\begin{array}{l}\text { S. } \\
\text { No }\end{array}$ & Class & Name of Alkaloid & Fungal isolate & Host & Function & Reference \\
\hline 1 & $\begin{array}{l}\text { Azaphilone } \\
\text { alkaloid }\end{array}$ & $\begin{array}{l}\text { N- } \\
\text { glutarylchaetoviridins } \\
\text { A }-\mathrm{C}\end{array}$ & $\begin{array}{l}\text { Chaetomium } \\
\text { globosum }\end{array}$ & $\begin{array}{l}\text { Deep sea } \\
\text { sediment } \\
\text { sample } \\
\text { collected in } \\
\text { south china } \\
\text { sea }\end{array}$ & $\begin{array}{l}\text { Exhibited a broad spectrum of } \\
\text { cytotoxicity toward MGC }-803 \text { and } \\
\text { HO8910 with the inhibition } \\
\text { concentration (IC50) values of } 6.6 \\
\text { and } 9.7 \mu \mathrm{M}\end{array}$ & $\begin{array}{l}\text { Sun et al., } \\
2019\end{array}$ \\
\hline 2 & $\begin{array}{l}\text { Benzodiazepine } \\
\text { alkaloids }\end{array}$ & Circumdatin A-C & $\begin{array}{l}\text { Aspergillus } \\
\text { ochraceus }\end{array}$ & & $\begin{array}{l}\text { Utilized for Gastrointestinal and } \\
\text { central nervous system disorders }\end{array}$ & $\begin{array}{l}\text { Rahbaek et } \\
\text { al., } 1999\end{array}$ \\
\hline 3 & $\begin{array}{l}\text { Benzodiazepine } \\
\text { and indole } \\
\text { alkaloids }\end{array}$ & $\begin{array}{l}\text { Circumdatins } \mathrm{K} \text { and } \mathrm{L} \\
\text { and } 5- \\
\text { chlorosclerotiamide }\end{array}$ & $\begin{array}{l}\text { Aspergillus } \\
\text { westerdijikiae }\end{array}$ & Deep sea & $\begin{array}{l}\text { Exhibited cytotoxicity toward human } \\
\text { carcinoma cell lines }\end{array}$ & $\begin{array}{l}\text { Peng et al., } \\
2013\end{array}$ \\
\hline 4 & $\begin{array}{l}\text { Clavine } \\
\text { alkaloids }\end{array}$ & $\begin{array}{l}\text { Fumigaclavine } \mathrm{A} \text { and } \\
\mathrm{B}\end{array}$ & $\begin{array}{l}\text { Aspergillus } \\
\text { fumigatus Fres }\end{array}$ & osprey & & $\begin{array}{l}\text { Spilsbury et } \\
\text { al., } 1961\end{array}$ \\
\hline 5 & $\begin{array}{l}\text { Clavinet type } \\
\text { alkaloid }\end{array}$ & $\begin{array}{l}\text { Triseclavine and } \\
\text { isosetoclavine }\end{array}$ & $\begin{array}{l}\text { Elymus type } \\
\text { ergot fungus, } \\
\text { Agropyrum } \\
\text { type fungus }\end{array}$ & $\begin{array}{l}\text { Pennisetum } \\
\text { typhoideum } \\
\text { Rich }\end{array}$ & Pharmacological functions & $\begin{array}{l}\text { Abe } \text { et al., } \\
2014\end{array}$ \\
\hline 6 & $\begin{array}{l}\text { Diastereomeric } \\
\text { quinolinonealka } \\
\text { loids }\end{array}$ & Peniprequinolone & $\begin{array}{l}\text { Penicillium } \\
\text { janczewskii }\end{array}$ & $\begin{array}{l}\text { Marine } \\
\text { sample }\end{array}$ & $\begin{array}{l}\text { Exhibited average cytotoxicity on } \\
\text { cancer cell lines }\end{array}$ & $\begin{array}{l}\text { He et al., } \\
2005\end{array}$ \\
\hline 7 & $\begin{array}{l}\text { Diketopiperazin } \\
\text { e alkaloid }\end{array}$ & Penicillivinacine & $\begin{array}{l}\text { Penicillium } \\
\text { vinaceum }\end{array}$ & $\begin{array}{l}\text { Marine } \\
\text { derived }\end{array}$ & $\begin{array}{l}\text { Exhibited antimigratory functions } \\
\text { toward the highly metastatic triple } \\
\text { negative human breast cancer cells }\end{array}$ & $\begin{array}{l}\text { Asiri et al., } \\
2015\end{array}$ \\
\hline 8 & $\begin{array}{l}\text { Diketopiperazin } \\
\text { e alkaloid }\end{array}$ & $\begin{array}{l}\text { Chrysopiperazines A } \\
\text { and B }\end{array}$ & $\begin{array}{l}\text { Penicillium } \\
\text { chrysogenum }\end{array}$ & $\begin{array}{l}\text { Gorgonian } \\
\text { derived }\end{array}$ & Antimicrobial activity & $\begin{array}{l}\text { Xu et al., } \\
2019\end{array}$ \\
\hline 9 & $\begin{array}{l}\text { Diketopiperazin } \\
\text { e alkaloids }\end{array}$ & Effusin A & $\begin{array}{l}\text { Aspergillus } \\
\text { effuses } \mathrm{H} 1-1\end{array}$ & $\begin{array}{l}\text { Mangrove } \\
\text { rhizosphere } \\
\text { soil }\end{array}$ & $\begin{array}{l}\text { Showed cytotoxic activities on P388 } \\
\text { cells }\end{array}$ & $\begin{array}{l}\text { Gao et al., } \\
2012\end{array}$ \\
\hline 10 & $\begin{array}{l}\text { Diketopiperazin } \\
\text { e alkaloids }\end{array}$ & $\begin{array}{l}\text { Golmaenone, } \\
\text { neoechinulin A }\end{array}$ & $\begin{array}{l}\text { Aspergillus } \\
\text { species }\end{array}$ & $\begin{array}{l}\text { Marine } \\
\text { derived }\end{array}$ & $\begin{array}{l}\text { Displayed a significant radical } \\
\text { scavenging activity toward } 1,1- \\
\text { diphenyl -2-picrylhydrazyl with } \\
\text { inhibition concentration (IC50) } \\
\text { values of } 20 \text { and } 24 \mu \mathrm{M} \text {, and also } \\
\text { Using as sunscreen }\end{array}$ & $\begin{array}{l}\text { Li } \text { et al., } \\
2004\end{array}$ \\
\hline 11 & $\begin{array}{l}\text { Dioxopiperazine } \\
\text { alkaloid }\end{array}$ & $\begin{array}{l}\text { Dehydroxybisdethiob } \\
\text { is(methylthio)gliotoxi } \\
\mathrm{n}\end{array}$ & $\begin{array}{l}\text { Pseudallescheri } \\
\text { a }\end{array}$ & $\begin{array}{l}\text { Marine } \\
\text { derived } \\
\text { fungus } \\
\text { culture }\end{array}$ & $\begin{array}{l}\text { Showed potent antibacterial activity } \\
\text { toward the methicillin - resistant and } \\
\text { multidrug - resistant staphylococcus } \\
\text { aureus }\end{array}$ & $\begin{array}{l}\text { Li et al., } \\
2006\end{array}$ \\
\hline 12 & $\begin{array}{l}\text { Epipolythiodiox } \\
\text { opiperazine }\end{array}$ & $\begin{array}{l}\text { Verticillin A, H, } \\
\text { gliocladicillin A, C }\end{array}$ & Bionectriaceae & & $\begin{array}{l}\text { Exhibited cytotoxicity toward a panel } \\
\text { of human malignant cell lines }\end{array}$ & $\begin{array}{l}\text { Figueroa } \text { et } \\
\text { al., } 2012\end{array}$ \\
\hline 13 & Ergot alkaloid & $\begin{array}{l}\text { Clavine alkaloid, D- } \\
\text { lysergic acid and its } \\
\text { derivatives and } \\
\text { ergopeptines }\end{array}$ & Claviceps & cereals & $\begin{array}{l}\text { Used in pharmatech industry, where } \\
\text { they utilized for synthesis of anti - } \\
\text { migraine drugs, uterotonics, prolactin } \\
\text { inhibitors and antiparkinsonian } \\
\text { agents }\end{array}$ & $\begin{array}{l}\text { Hulvova et } \\
\text { al., } 2013\end{array}$ \\
\hline 14 & Ergot alkaloid & $\begin{array}{l}\text { Elymoclavine }-\mathrm{O}-\beta \\
-\mathrm{D}-\text { fructoside }\end{array}$ & $\begin{array}{l}\text { Claviceps } \\
\text { strain SD } 58\end{array}$ & & $\begin{array}{l}\text { Pharmacological activities (Pain } \\
\text { releivers) }\end{array}$ & $\begin{array}{l}\text { Flieger et } \\
\text { al., } 1989\end{array}$ \\
\hline
\end{tabular}


Archana O \& Praveen Kumar Nagadesi; Saudi J Pathol Microbiol, Jan, 2022; 7(1): 4-19

\begin{tabular}{|c|c|c|c|c|c|c|}
\hline 15 & Ergot alkaloids & $\begin{array}{l}\text { Clavines, ergonovine } \\
\text { alkaloids }\end{array}$ & $\begin{array}{l}\text { Claviceps } \\
\text { purpurea }\end{array}$ & Rice & & $\begin{array}{l}\text { Tsai et al., } \\
1995\end{array}$ \\
\hline 16 & $\begin{array}{l}\text { Ergot and } \\
\text { clavine } \\
\text { alkaloids }\end{array}$ & $\begin{array}{l}\text { Chanoclavine, } \\
\text { agroclavine, } \\
\text { penniclavine, } \\
\text { elymoclavine, } \\
\text { ergonovine, } \\
\text { ergonovinine }\end{array}$ & $\begin{array}{l}\text { Balansia } \\
\text { epichole }\end{array}$ & Smut grass & & $\begin{array}{l}\text { Bacon et al., } \\
1979\end{array}$ \\
\hline 17 & $\begin{array}{l}\text { Imidazolone } \\
\text { alkaloids }\end{array}$ & Tricladins $\mathrm{A}$ and $\mathrm{B}$ & $\begin{array}{l}\text { Tricladium } \\
\text { species }\end{array}$ & & $\begin{array}{l}\text { Exhibited marginal cytotoxicity } \\
\text { toward MDA - mb-231 human } \\
\text { breast cancer cells }\end{array}$ & $\begin{array}{l}\text { Zou et al., } \\
2011\end{array}$ \\
\hline 18 & $\begin{array}{l}\text { Indole } 2,5- \\
\text { diketopiperazine } \\
\text { alkaloids }\end{array}$ & Eurotiumins $\mathrm{A}-\mathrm{E}$ & $\begin{array}{l}\text { Marine derived } \\
\text { fungus } \\
\text { Eurotium sp. } \\
\text { SCSIO F452 }\end{array}$ & $\begin{array}{l}\text { South china } \\
\text { sea sediment } \\
\text { sample }\end{array}$ & $\begin{array}{l}\text { Exhibited important radical } \\
\text { scavenging functions toward DPPH }\end{array}$ & $\begin{array}{l}\text { Zhong et } \\
\text { al., } 2018\end{array}$ \\
\hline 19 & Indole alkaloid & $\begin{array}{l}\text { Communesins } \mathrm{G} \text { and } \\
\mathrm{H}\end{array}$ & $\begin{array}{l}\text { Penicillium } \\
\text { rivulum } \\
\text { Frisvad }\end{array}$ & & $\begin{array}{l}\text { Inactive in antimicrobial, antiviral } \\
\text { and anticancer assays }\end{array}$ & $\begin{array}{l}\text { Dalsgaard } e t \\
\text { al., } 2005\end{array}$ \\
\hline 20 & Indole alkaloid & $\begin{array}{l}\text { 7- } \\
\text { chlorofischerindoline }\end{array}$ & $\begin{array}{l}\text { Neosartorya } \\
\text { hiratsukae }\end{array}$ & & $\begin{array}{l}\text { Exhibited antibacterial and cytotoxic } \\
\text { activity }\end{array}$ & $\begin{array}{l}\text { Paluka } \text { et } \\
\text { al., } 2020\end{array}$ \\
\hline 21 & Indole alkaloids & $\begin{array}{l}\text { Hirsutellones A - E } \\
\text { alkaloids }\end{array}$ & $\begin{array}{l}\text { Hirsutella } \\
\text { nivea } \\
\text { BCC2594 } \\
\text { (insect } \\
\text { pathogenic } \\
\text { fungus) }\end{array}$ & & $\begin{array}{l}\text { Exhibited important growth } \\
\text { inhibitory activity toward } \\
\text { Mycobacterium tuberculosis H37Ra }\end{array}$ & $\begin{array}{l}\text { Isaka et al., } \\
2005\end{array}$ \\
\hline 22 & Indole alkaloids & Notoamides A-D & $\begin{array}{l}\text { Aspergillus } \\
\text { species }\end{array}$ & & $\begin{array}{l}\text { Notoamides A-C, Exhibited average } \\
\text { cytotoxicity toward cancer cell lines }\end{array}$ & $\begin{array}{l}\text { Kato, et al. } \\
2007\end{array}$ \\
\hline 23 & Indole alkaloids & $\begin{array}{l}\text { Shearinines D, E and } \\
\text { F }\end{array}$ & $\begin{array}{l}\text { Penicillium } \\
\text { Janthinellum } \\
\text { Biourge }\end{array}$ & & $\begin{array}{l}\text { Induce apoptosis in human Leukemia } \\
\text { HL-60 cells }\end{array}$ & $\begin{array}{l}\text { Smetanina } \\
\text { et al., } 2007\end{array}$ \\
\hline 24 & Indole alkaloids & $\begin{array}{l}\text { 17-epi-notoamides } \mathrm{Q} \\
\text { and } \mathrm{M}\end{array}$ & $\begin{array}{l}\text { Aspergillus } \\
\text { species }\end{array}$ & & $\begin{array}{l}\text { Exhibited antibacterial activity } \\
\text { toward Staphylococcus epidermidis }\end{array}$ & $\begin{array}{l}\text { Chen } \text { et al., } \\
2013\end{array}$ \\
\hline 25 & Indole alkaloids & $\begin{array}{l}\text { Fumigatosides E and } \\
\mathrm{F}\end{array}$ & $\begin{array}{l}\text { Aspergillus } \\
\text { fumigatus }\end{array}$ & Deep sea & Showed antifungal activity & $\begin{array}{l}\text { Limbadri, et } \\
\text { al., } 2018\end{array}$ \\
\hline 26 & Indole alkaloids & Glyantrypine & $\begin{array}{l}\text { Cladosporium } \\
\text { species. PJX- } \\
41\end{array}$ & $\begin{array}{l}\text { Mangrove } \\
\text { derived } \\
\text { fungus }\end{array}$ & $\begin{array}{l}\text { Showed important effects toward } \\
\text { influenza virus A (H1N1) }\end{array}$ & $\begin{array}{l}\text { Peng et al., } \\
2013\end{array}$ \\
\hline 27 & Indole alkaloids & $\begin{array}{l}\text { Chaetoglobinol A, } \\
\text { Chaetocochin J }\end{array}$ & $\begin{array}{l}\text { Chaetomium } \\
\text { globosum }\end{array}$ & Rice culture & $\begin{array}{l}\text { Showed antibacterial activities } \\
\text { toward Bacillus subtilis }\end{array}$ & $\begin{array}{l}\text { Xu et al., } \\
2015\end{array}$ \\
\hline 28 & Indole alkaloids & $\begin{array}{l}\text { 4-(3-indolyl) butane- } \\
\text { 1,2,3-triol; 3-(3,3- } \\
\text { diindolyl) propane- } \\
\text { 1,2-diol; and 3-(3- } \\
\text { indolyl) propane - } \\
\text { 1,2,3-triol }\end{array}$ & $\begin{array}{l}\text { Balansia } \\
\text { epichole } \\
\text { (Weese) }\end{array}$ & $\begin{array}{l}\text { Laboratory } \\
\text { culture }\end{array}$ & Parasitizes pasture grasses & $\begin{array}{l}\text { Porter } \text { et al., } \\
1977\end{array}$ \\
\hline 29 & $\begin{array}{l}\text { Indole based } \\
\text { cytochalasanalk } \\
\text { aloids }\end{array}$ & $\begin{array}{l}\text { Armochaeglobines A } \\
\text { and B }\end{array}$ & $\begin{array}{l}\text { Chaetomium } \\
\text { globosum }\end{array}$ & $\begin{array}{l}\text { Arthropod } \\
\text { derived, } \\
\text { Armadillidiu } \\
m \text { vulgare }\end{array}$ & $\begin{array}{l}\text { Anticancer activity on human cell } \\
\text { lines }\end{array}$ & $\begin{array}{l}\text { Chen } \text { et al., } \\
2015\end{array}$ \\
\hline 30 & $\begin{array}{l}\text { Indole } \\
\text { diketopiperazine } \\
\text { alkaloids }\end{array}$ & $\begin{array}{l}\text { Spirotryprostatins C- } \\
\text { E, 13- } \\
\text { oxoverruculogen }\end{array}$ & $\begin{array}{l}\text { Aspergillus } \\
\text { fumigatus }\end{array}$ & Holothurian & Exhibited cytotoxic activities & $\begin{array}{l}\text { Wang et al., } \\
2008\end{array}$ \\
\hline 31 & $\begin{array}{l}\text { Isoechinulin } \\
\text { type alkaloids }\end{array}$ & $\begin{array}{l}\text { Neoechinulin A, } \\
\text { Preechinulin, } \\
\text { Isoechinulin A }\end{array}$ & $\begin{array}{l}\text { Nigrospora } \\
\text { genus }\end{array}$ & $\begin{array}{l}\text { Soft coral } \\
\text { Dendronepht } \\
\text { hya sp. }\end{array}$ & $\begin{array}{l}\text { Showed antifouling activities toward } \\
\text { the larval settlement of barnacle } \\
\text { Balanus Amphitrite }\end{array}$ & $\begin{array}{l}\text { Sun et al., } \\
2014\end{array}$ \\
\hline 32 & $\begin{array}{l}\text { Isoquinoline } \\
\text { alkaloid }\end{array}$ & Ampullosine & $\begin{array}{l}\text { Sepadonium } \\
\text { ampullosporu } \\
m\end{array}$ & & $\begin{array}{l}\text { Exhibited antifungal activity toward } \\
\text { the phytopathogenic fungus } \\
\text { Cladosporium cucumerinum }\end{array}$ & $\begin{array}{l}\text { Quang et } \\
\text { al., } 2010\end{array}$ \\
\hline 33 & $\begin{array}{l}\text { Mixture of } \\
\text { quaternary } \\
\text { alkaloid }\end{array}$ & $\begin{array}{l}\text { Tannic, caffeic and } \\
\text { ferulic acids }\end{array}$ & $\begin{array}{l}\text { Argemone } \\
\text { Mexicana }\end{array}$ & & Exhibited antifungal activity & $\begin{array}{l}\text { Singh et al., } \\
2010\end{array}$ \\
\hline 34 & $\begin{array}{l}\text { Pentacyclic } \\
\text { spiroindolinone } \\
\text { alkaloid }\end{array}$ & Citrinadin A & $\begin{array}{l}\text { Marine derived } \\
\text { fungus, } \\
\text { Penicillium } \\
\text { citrinum }\end{array}$ & $\begin{array}{l}\text { Marine red } \\
\text { alga }\end{array}$ & Showed antimicrobial activity & $\begin{array}{l}\text { Tsuda et al., } \\
2004\end{array}$ \\
\hline 35 & $\begin{array}{l}\text { Peptide ergot } \\
\text { alkaloid }\end{array}$ & $\gamma$-ergokryptinine & $\begin{array}{l}\text { Claviceps } \\
\text { purpurea } \mathrm{CCM} \\
8059\end{array}$ & & $\begin{array}{l}\text { Used in agriculture and medical } \\
\text { fields }\end{array}$ & $\begin{array}{l}\text { Cvak et al., } \\
2005\end{array}$ \\
\hline
\end{tabular}


Archana O \& Praveen Kumar Nagadesi; Saudi J Pathol Microbiol, Jan, 2022; 7(1): 4-19

\begin{tabular}{|c|c|c|c|c|c|c|}
\hline 36 & $\begin{array}{l}\text { Piperazine } \\
\text { alkaloid }\end{array}$ & Herquline alkaloid & $\begin{array}{l}\text { Penicillium } \\
\text { herquei } \text { Fg-372 }\end{array}$ & $\begin{array}{l}\text { Soil sample } \\
\text { collected at } \\
\text { Saitama } \\
\text { Prefecture, } \\
\text { Japan }\end{array}$ & $\begin{array}{l}\text { Inhibits blood platelet aggregation } \\
\text { induced by adenosine diphosphate }\end{array}$ & $\begin{array}{l}\text { Omura } \text { et } \\
\text { al., } 1979\end{array}$ \\
\hline 37 & $\begin{array}{l}\text { Prenylated } \\
\text { indole alkaloids }\end{array}$ & Asperversiamides & $\begin{array}{l}\text { Aspergillus } \\
\text { versicolor }\end{array}$ & $\begin{array}{l}\text { Marine } \\
\text { derived }\end{array}$ & $\begin{array}{l}\text { Showed anti-inflammatory } \\
\text { activities }\end{array}$ & $\begin{array}{l}\text { Li } \text { et al., } \\
2018\end{array}$ \\
\hline 38 & $\begin{array}{l}\text { Prenylated } \\
\text { indole alkaloids }\end{array}$ & $\begin{array}{l}17-\mathrm{O}- \\
\text { ethylnotoamide } \mathrm{M}\end{array}$ & $\begin{array}{l}\text { Aspergillus } \\
\text { sulphureus and } \\
\text { Isaria felina }\end{array}$ & $\begin{array}{l}\text { Marine } \\
\text { derived fungi }\end{array}$ & $\begin{array}{l}\text { Inhibit the formation of colony of the } \\
\text { human prostate malignant cells } \\
22 \mathrm{Rv} 1 \text { at non - cytotoxic of } 10 \mu \mathrm{M}\end{array}$ & $\begin{array}{l}\text { Afiyatullov } \\
\text { et al., } 2018\end{array}$ \\
\hline 39 & $\begin{array}{l}\text { Prenylated } \\
\text { indole alkaloids }\end{array}$ & Speramides A & $\begin{array}{l}\text { Aspergillus } \\
\text { ochraceus } \\
\text { KM007 }\end{array}$ & $\begin{array}{l}\text { Fresh water } \\
\text { derived }\end{array}$ & $\begin{array}{l}\text { Displayed moderate activity toward } \\
\text { Pseudomonas aeruginosa with a } \\
\text { minimum inhibition concentration } \\
\text { (MIC) value of } 0.8 \mu \mathrm{M}\end{array}$ & $\begin{array}{l}\text { Chang et } \\
\text { al., } 2016\end{array}$ \\
\hline 40 & $\begin{array}{l}\text { Pyridinone } \\
\text { alkaloid }\end{array}$ & $\begin{array}{l}\text { 1,4-dihydroxy-5- } \\
\text { phenyl-2-pyridinone } \\
\text { alkaloid }\end{array}$ & $\begin{array}{l}\text { Septoria } \\
\text { pistaciarum }\end{array}$ & & $\begin{array}{l}\text { Showed average in vitro antimalarial } \\
\text { activities toward chloroquine - } \\
\text { sensitive (D6) and resistant (W2) } \\
\text { strains of plasmodium falciparum } \\
\text { and also active toward both } \\
\text { methicillin - sensitive and } \\
\text { methicillin - resistant staphylococcus } \\
\text { aureus }\end{array}$ & $\begin{array}{l}\text { Kumariham } \\
\text { y et al., } \\
2010\end{array}$ \\
\hline 41 & $\begin{array}{l}\text { Pyridone } \\
\text { alkaloid }\end{array}$ & Arthpyrones D - K & $\begin{array}{l}\text { Arthrinium sp. } \\
\text { UJNMF0008 }\end{array}$ & $\begin{array}{l}\text { Deep sea } \\
\text { derived }\end{array}$ & $\begin{array}{l}\text { Exhibited Average to significant } \\
\text { antibacterial activity toward } \\
\text { Mycobacterium smegmatis and } \\
\text { Staphylococcus aureus and also } \\
\text { exhibited cytotoxicity toward two } \\
\text { human Osteosarcoma cell lines }\end{array}$ & $\begin{array}{l}\text { Bao et al., } \\
2018\end{array}$ \\
\hline 42 & $\begin{array}{l}\text { Pyridone } \\
\text { alkaloid }\end{array}$ & Militarinones D & $\begin{array}{l}\text { Paecilomyces } \\
\text { militaris }\end{array}$ & & $\begin{array}{l}\text { Displayed cytotoxic activities and } \\
\text { negligible neuritogenic activity in PC } \\
-12 \text { cells }\end{array}$ & $\begin{array}{l}\text { Schmidt et } \\
\text { al., } 2003\end{array}$ \\
\hline 43 & $\begin{array}{l}\text { Pyridone } \\
\text { alkaloids }\end{array}$ & Arthpyrones A- C & $\begin{array}{l}\text { Arthrinium } \\
\text { arundinis } \\
\text { ZSDS1 - F3 }\end{array}$ & $\begin{array}{l}\text { Sponge } \\
\text { derived }\end{array}$ & Antimicrobial activity & $\begin{array}{l}\text { Wang } \text { et } \\
\text { al.,2015 }\end{array}$ \\
\hline 44 & $\begin{array}{l}\text { Pyrrole - } \\
\text { imidazole } \\
\text { alkaloids }\end{array}$ & Fungerin & $\begin{array}{l}\text { Fusarium } \\
\text { species }\end{array}$ & & Antifungal agent & $\begin{array}{l}\text { Kato et al., } \\
1996\end{array}$ \\
\hline 45 & $\begin{array}{l}\text { Pyrrole based } \\
\text { dimeric alkaloid }\end{array}$ & Hirsutellone A & $\begin{array}{l}\text { Trichoderma } \\
\text { gelatinosum } \\
\text { BCC7579 }\end{array}$ & & Anti - tubercular agent & $\begin{array}{l}\text { Supothina et } \\
\text { al., } 2007\end{array}$ \\
\hline 46 & $\begin{array}{l}\text { Pyrrolidine } \\
\text { alkaloids }\end{array}$ & $\begin{array}{l}\text { Aegyptolidines A and } \\
\text { B }\end{array}$ & $\begin{array}{l}\text { Aspergillus } \\
\text { aegyptiacus }\end{array}$ & $\begin{array}{l}\text { Cotton textile } \\
\text { yield }\end{array}$ & $\begin{array}{l}\text { Exhibited average cytotoxic effect on } \\
\text { murine lymphoma tumor cell line }\end{array}$ & $\begin{array}{l}\text { Ibrahim } \text { et } \\
\text { al., } 2015\end{array}$ \\
\hline 47 & $\begin{array}{l}\text { Pyrrolidinone } \\
\text { alkaloid }\end{array}$ & $\begin{array}{l}\text { Ascosalipyrrolidinone } \\
\text { A }\end{array}$ & $\begin{array}{l}\text { Ascochyta } \\
\text { salicorniae } \\
\text { (obligate } \\
\text { marine fungus) }\end{array}$ & $\begin{array}{l}\text { Green alga } \\
\text { Ulva species }\end{array}$ & $\begin{array}{l}\text { Showed anti-plasmodial effects } \\
\text { against Plasmodium falciparum } \\
\text { strains K1 and NF 54, and also } \\
\text { exhibited antimicrobial activity and } \\
\text { hindering tyrosine Kinase P56 }\end{array}$ & $\begin{array}{l}\text { Osterhage et } \\
\text { al., } 2000\end{array}$ \\
\hline 48 & $\begin{array}{l}\text { Quinazoline } \\
\text { alkaloid }\end{array}$ & Aurantiomides A-C & $\begin{array}{l}\text { Penicillium } \\
\text { aurantiogriese } \\
\text { um SP0-19 }\end{array}$ & Sponge & $\begin{array}{l}\text { Exhibited average cytotoxicity } \\
\text { toward HL-60, P388 and BEL-7402 } \\
\text { cell lines }\end{array}$ & $\begin{array}{l}\text { Xin et al., } \\
2007\end{array}$ \\
\hline 49 & $\begin{array}{l}\text { Quinazolinone } \\
\text { alkaloids }\end{array}$ & $\begin{array}{l}\text { Penipanoids A, B and } \\
\text { C }\end{array}$ & $\begin{array}{l}\text { Penicillium } \\
\text { paneum } \mathrm{SD}- \\
44\end{array}$ & $\begin{array}{l}\text { Marine } \\
\text { Sediment - } \\
\text { derived }\end{array}$ & Exhibited antimicrobial activity & $\begin{array}{l}\text { Li et al., } \\
2011\end{array}$ \\
\hline 50 & $\begin{array}{l}\text { Sesquiterpenoid } \\
\text { alkaloid }\end{array}$ & $\begin{array}{l}\text { Eurochevalierinealkal } \\
\text { oid }\end{array}$ & $\begin{array}{l}\text { Eurotium } \\
\text { chevalieri }\end{array}$ & & $\begin{array}{l}\text { Showed antimalarial functions } \\
\text { toward Mycobacterium tuberculosis, } \\
\text { and also exhibited cytotoxicity } \\
\text { toward cancer cell lines }\end{array}$ & $\begin{array}{l}\text { kanokmedh } \\
\text { akul } \text { et al., } \\
2011\end{array}$ \\
\hline 51 & $\begin{array}{l}\text { Spiroindolinone } \\
\text { alkaloids }\end{array}$ & $\begin{array}{l}\text { Cycloexpansamines } \\
\mathrm{A} \text { and B }\end{array}$ & $\begin{array}{l}\text { Penicillium sp. } \\
\text { (SF-5292) }\end{array}$ & & $\begin{array}{l}\text { Moderately inhibited the protein's } \\
\text { activity Tyrosine phosphatase 1B }\end{array}$ & $\begin{array}{l}\text { Lee } \text { et al., } \\
2015\end{array}$ \\
\hline 52 & $\begin{array}{l}\text { Tyrosine } \\
\text { alkaloids }\end{array}$ & $\begin{array}{l}\text { Gymnastatin Z, } \\
\text { Phomacin B and } \\
\text { Triticone D }\end{array}$ & $\begin{array}{l}\text { Westerdykella } \\
\text { dispersa }\end{array}$ & $\begin{array}{l}\text { Marine } \\
\text { sediment }\end{array}$ & $\begin{array}{l}\text { Exhibited antibacterial and cytotoxic } \\
\text { activities on human malignant cancer } \\
\text { cell line }\end{array}$ & $\begin{array}{l}\text { Xu et al., } \\
2017\end{array}$ \\
\hline 53 & $\begin{array}{l}\text { Zwitterionic } \\
\text { sesquiterpene } \\
\text { alkaloid }\end{array}$ & Consoramides $\mathrm{A}-\mathrm{C}$ & Irpex consors & Culture broth & $\begin{array}{l}\text { Exhibited antibacterial and } \\
\text { antioxidant properties }\end{array}$ & $\begin{array}{l}\text { Kim et al., } \\
2021\end{array}$ \\
\hline
\end{tabular}




\section{APPLICATIONS}

\section{BIOLOGICAL ROLES OF ENDOPHYTIC FUNGI}

The potentiality of endophytic fungi is to synthesize new and notable bioactive secondary metabolites. These are more significant in the field of Pharmaceutical, industrial and agriculture. The several natural resources synthesized by endophytic fungi contain identical structures and bioactivities toward different diseases. Instead of a vast bund, this dedicates huge capabilities for oppression of secondary yields for medicinal, agricultural and industrial utilization.

\section{NUTRIENT PEDALLING}

It is an important procedure that appears enduringly to balance nutrients and wreak them accessible for each element of the environment.

The decadence of the dead biomass evolved into one crucial step to carryback used nutrients to the ecosystem, which in return else becomes available to the living beings. The primary significant characterizations in biodegradation to the trashery of its host plants. They have capacity to disintegrate involute substances into candid form.

Another significant characterization is bioremediation, which explains as a custom of uncapping of pollutants and eyas from the atmosphere by the utilize of microorganisms. It depends on the utilize of microorganisms. It depends on the life procedure of microbes to disintegrate these wastes substances and it has become contingent due to innumerable microbial variety.

\section{PHOTOSTIMULATION}

Endophytes also takepart in the uptake of necessary nutrients essential for plant growth. They educe uptake of Nitrogen and in giant fescue adjustment to Phosphorous blemish. A novel strain of fungus Cladosporium sphaerospermum extracted from the glycine max (L) Merr roots. Exhibited the aura of higher aggregates of bioactive GA3, GA4 and GA7, which persuade inordinate plant growth in both rice and soyabean types. The endophytes roles are thoroughly recorded forharborage of plant in soil, absorption of nutrient storage, water and ion and vegetative growth of plants, the root system is in close relationship with a broad range of soil microbial populations.

\section{ENDOPHYTES IN TISSUE CULTURE}

Endophytes are principally precious to the host plants and for plant tissue culture. The ideal host plants and for plant tissue culture. The ideal goal of tissue culture is to grow uncontaminated plants. Even after stature fumigation of the explants, autoclaving and ultraviolet treatment of nutrient medium for tissue culture, endophytic fungi/ bacteria/ actinomycetes start developing from tissue cultured explant. These endophytes are commonly contemplated as pollutants impacting in complete waste of time, media and explants and also imperiled species of microbes, can be protected by this technique. Also, endophytic species constitution and plant genotype in conjunction under tissue culture circumstances are the basic ingredient for accomplishment of plant tissue cultures with promoted resumption potentiality. Interconnection between the endophytes and particular secondary compounds filtered from plant may be an utmost surface for darkening or browning and cell death, some endophytes were extracted in broth / cultures from roots and plant photosynthetic tissues.

\section{ANTIVIRAL ACTIVITY}

The alluring utilize of antibiotic products from endophytic fungi are the obstruction of viral growth. Two novel human cytomegalovirus protease hinders, cytonic acids $\mathrm{A}$ and $\mathrm{B}$ were illuminated by using mass spectrometry and nuclear magnetic resonance techniques and obtained to be effective toward virus growth. Some metabolites from endophytic fungi of xerophytic plants serve as a feasible source for recognizing paladin inhibitors of Human Immunodeficiency virus 1 replication.

\section{ANTICANCER ACTIVITY}

Paclitaxel and some of its derivatives indicate the top crucial category of antitumor agents generated by endophytes. The method of work of paclitaxel is to intercept tubulin molecules from depolymerizing throughout the cell division procedure. It is the first billion dollars anticancer drug in the world and which is utilized to trat a numerous tissues of human proliferating disease. Taxomyces andreanae lay out an another for synthesis of taxol through torreyanic acid is another significant antitumor agent synthesized from $P$. microspore extractedfrom $T$. taxifolia.

Hypocera Lixii, a novel endophytic fungus synthesized Cajanol, an anticancer agent, which is extracted from Cajanus cajan. First time, the endophytic fungus $M$. fragilis is capable to synthesize these bioactive metabolites, scilicet, Podophyllotoxin and Kaempferol. Also, Guanacastane diterpenoids described from the plant endophytic fungus Cercospora species.

\section{ANTIDIABETIC ACTIVITY}

A non-peptidal fungal metabolite was extracted from an endophytic fungus Pseudomassaria species gathered from an African rainforest. The nature has given enormous natural resources, which can be expurgated for their medicinal utilizations. The antidiabetic and hypolipidemic activity of endophytic fungi extracted from Salvadora oleoides in glucose aristrocrat, fasting and alloxan fomentation diabetic Wistar albino rats and inquest new antidiabetic drugs 
Archana O \& Praveen Kumar Nagadesi; Saudi J Pathol Microbiol, Jan, 2022; 7(1): 4-19

from fungal endophytes name as Aspergillus species, Phoma species, and some unknown species; those noticeably decrease blood glucose level by glucose endurance test. $\alpha$ - amylase obstructive - generating endophytic actinomycetes from the leaves and stem of Leucas ciliate and Rauwolfia densiflora, two of the popular medicinal plants utilized in the diabetic treatment.

\section{IMMUNOSUPPRESSIVE ACTIVITY}

An endophytic fungus Fusarium subglutinans extracted from $T$. wilfordii generates subglutinol A and $\mathrm{B}$, which function as the immunosuppressive agent. Now days, these drugs are used to deter allograft dismissal in transplant patients and in coming days they could be utilized to treat autoimmune disease like rheumatoid arthritis and insulin dependent diabetes. Pestaloside, pestalpyrone and hydroxyl pestalopyrone extracted from P. microspore contains plant toxic features. Pseudomycins are antifungal substances, these are antifungal substances, and these substances exhibited strong effectiveness toward human pathogen Candida albicans, which are peptide antibiotics possessing remarkable amino acids such as L - hydroxy aspartic acid, L -chlorothreonine and the two D and L diaminobutyric acid. Ambuic acid which is a cyclohexanone juncture to the Pseudomycins family extracted from Pestalotiopsis microsporeand effective toward human pathogens. Munumbicins, which is a bioactive substance, extracted from Streptomyces species. Which are more effective towards gram negative and as well as gram positive bacteria. Munumbicins E -4 and $\mathrm{E}-5$ exhibited antimalarial functions, this was more effective as compared with that of chloroquine.

\section{ACKNOWLEDGEMENT}

We thank the college management of St. Joseph's College (Autonomous), Bangalore for providing the laboratory facilities and constant encouragement.

\section{REFERENCES}

1. Abe. M., Yamatodani. S., Yamano. T., \& Kusumoto. M. (2014). Relationship between Triseclavine and Isosetoclavine, Bull. Agr. Chem. Soc., 22(1); 59-60, https://doi.org/10.1080/03758397.1958.10857438

2. Afiyatullov. S. S., Zhuravleva O. I., Antonov A. S., Berdyshev D. V., Pivkin. M. V. Denisenko. V. A., Popov. R. S., Gerasimenko. A. V., Amsberg G. V., Dyshlovoy. S. A., Leshchenko. E. V., \& Yurchenko, A. N. (2018). Prenylated indole alkaloids from co - culture of marine - derived fungi Aspergillus sulphureus and Isaria feline. J Antibiot. $71(10): 846 \quad-853$, https://doi.org/10.1038/s41429-018-0072-9

3. Agusta, A., Wulansari, D., Nurkanto, A., \& Fathoni, A. (2014). Biotransformation of protoberberine alkaloids by the endophytic fungus Coelomycetes AFKR-3 isolated from yellow moonsheed plant (ArchangelisiaFlava) Merr. Procedia Chemistry, 13:38-43. https://doi.org/10.1016/j.proche.2014.12.004

4. An, C.Y., Li X.M., Li C.S., M.H. Wang, Xu G.M., \& Wang, B.G. (2013). Aniquinazolines A-D, four new quinazolinone alkaloids from marine derived endophytic fungus Aspergillus nidulans. Mar. Drugs 11(7): 2682-2694, https://doi.org/10.3390/md11072682

5. Asiri, I.A.M, Badr, J. M., \& Youssef, D.T.A. (2015). Penicillivinacine, antimigratory diketopiperazine alkaloid from the marine derived fungus Penicillium vinaceum, Phytochemistry letters, 13: 53 - 58, https://doi.org/10.1016/j.phytol.2015.05.014

6. Bacon, C. W., Porter J. K., \& Robbins J. D. (1979). Laboratory production of Ergot alkaloids by species of Balansia, Microbiology, 113(1); 119 126.

7. Bao. J, Zhai. H, Zhu. K, Yu J.H., Zhang. Y., Wang. Y., Jiang C.S., Zhang, X.Y., Zhang, Y, Zhang. H. (2018), Bioactive pyridine alkaloids from a deep sea - derived fungus Arthrinium sp. UJNMF0008, Marine Drugs, 16(5):174, https://doi.org/10.3390/md16050174

8. Barros. F. A. P., \& Edson Filho. (2005). Four Spiroquinazoline alkaloids from Eupenicillium sp. isolated as an endophytic fungus from leaves of Murraya paniculate (Ruataceae). Biochemical Systematics and Ecology, 33(3); 257 - 268. https://doi.org/10.1016/j.bse.2004.09.002

9. Blankenship J.D., Spiering, M.J., Wilkinson, H., Fannin, F., Bush, L.P., \& Schardl, C.L. (2001). Production of loline alkaloids by the grass endophyte, Neotyphodium uncinatum, in defined media, Phytochemistry, 58(3); 395-401, https://doi.org/10.1016/S0031-9422(01)00272-2

10. Chang. Y. W., Yuan. C. M., Zhang. J., Liu. S., Cao. P., Hua. H. M., Di. Y. T, Hao. X. J. (2016). Speramides A - B, two new prenylated indole alkaloids from the freshwater - derived fungus Aspergillus ochraceus KM007. Tetrahedron Letters. 57(45):4952 - 4955, https://doi.org/10.1016/j.tetlet.2016.09.071

11. Chen, C., Zhu, H., Li X.N., Yang, J., Wang, J., Li, G., Li Y., Tong, Q., Yao, G., Luo, Z., Xue, Y., \& Zhang, Y. (2015). Armochaeglobines A and B, two new indole - based alkaloids from the arthropod derived fungus Chaetomium globosum, Org. Lett, 17(3); 644-647, https://doi.org/10.1021/o1503666b

12. Chen. M, Shao. C. L, Fu. X. M, Xu. R. F, Zheng. J. J, Zhao. D. L, She. Z. G and Wang. C. Y. (2013). Bioactive indole alkaloids and phenyl ether derivatives from a marine - derived Aspergillus sp. Fungus, J. Nat. Prod., 76(4); 547 - 553, https://doi.org/10.1021/np300707x 
Archana O \& Praveen Kumar Nagadesi; Saudi J Pathol Microbiol, Jan, 2022; 7(1): 4-19

13. Cook, D., Gardner, D. R., \& Pfister, J. A. (2014). Swainsonine - containing plants and their relationship to endophytic fungi, J. Agric. Food chem.,62(30);

7326-7334, https://doi.org/10.1021/jf501674r

14. Cvak. L, Jegorov. A, Sedmera. P, Cisarova. I, Cejka. J, Kratochvil. B., \& Pakhomova. S, Norleucine. (2005). Norleucine, a natural occurrence in a novel ergot alkaloid $\gamma$ ergokryptinine, Springer Nature, 29,145 150,https://doi.org/10.1007/s00726-005-0180-2

15. Daley. S. K., \& Cordell. G. A. (2021). Biologically significant and recently isolated alkaloids from endophytic fungi. J. Nat, Prod. 84(3); 871-897 https://doi.org/10.1021/acs.jnatprod.0c01195

16. Dalsgaard. P. W., Blunt. J. W, Munro. M. H. G, Frisvad. J. C., \& Christophersen. C. (2005).Communesins $\mathrm{G}$ and $\mathrm{H}$, new alkaloids from the Psychrotolerant fungus Penicillium rivulum, J. Nat. $\quad$ Prod., 68(2); 258-261, https://doi.org/10.1021/np049646i

17. Dissanayake. R. K., Ratnaweera P.B, Williams D. E, Wijayarathne. C. D, Wijesundera. R. L.C., Anderson, R. J., \& Silva. E. D.D. (2016). Antimicrobial activities of mycoleptodiscin B isolated from endophytic fungus Mycoleptodiscus sp. of Calamus thwaitesii Becc., Journal of Applied Pharmaceutical Science., 6(1); 001-006, https://doi.org/10.73244/JAPS.2016.600101

18. Du F.Y., Li X., Li, C.S., \& Shang, Z. (2012). Cristatumins A-D, new indole alkaloids from the marine - derived endophytic fungus Eurotium cristatum EN -220.Phytochemistry Letters. 22(14): 4650-4653, https://doi.org/10.1016/j.bmcl.2012.05.088

19. Du, F.Y., Li X., Li X.M., Zhu L.W., \& Wang, B.G. (2017). Indole diketopiperazine alkaloids from Eurotium cristatum EN - 220, an endophytic fungus isolated from the marine alga Sargassum thunbergia. Marine 15(2),https://doi.org/10.3390/md15020024

20. Feng. C., \& Ma. Y. (2010). Isolation and anti phytopathogenic activity of secondary metabolites from Alternaria sp. FL25, an endophytic fungus in Ficuscarica. Chinese Journal of applied and Environmental Biology, 16(1);76-78, https://doi.org/10.3724/SP.J.1145.2010.00076

21. Figueroa. M., Graf. T.N., Ayers. S., Adcock. A. F., Kroll. D. J., Yang. J, Swanson. S.M, Acuna. U. M, Blanco. E.J.C.D, Agrawal. R., Wani. M.C, Darveaux, B.A., Pearce, C. J., Oberlies N. H. (2012). Cytotoxic epipolythiodioxopiperazine alkaloids from filamentous fungi of the Bionectriaceae, the journal of antibiotics., 65(11):559-564,https://doi.org/10.1038/ja.2012.69

22. Flieger. M., Zelenkova. N.F., Sedmera. P, Kren. V., Novak. J., Rylko. V., Sajdi, P., \& Rehacek. Z. (2004). Ergot alkaloid glycosides from saprophytic cultures of Claviceps, I.Elymoclavine fructosides,
J. Nat. Prod., 5(3); 506 - 510, https://doi.org/10.1021/np50063a007

23. Gao H., Liu W., Zhu T., Mo X., Mandi A., Kurtan T., Li J., Ai J.,Gu Q., \& Li D. (2012). Diketpiperazine alkaloids from a mangrove rhizosphere soil derived fungus Aspergillus effuses H1-1, Org. Biomol. Chem., 10: 9501-9506, https://doi.org/10.1039/C2OB26757H

24. Gao. N., Shang. Z. C., Yu. P., Luo. J., Jian. K. L., Kong. L. Y and Yang. M. H. (2017),Alkaloids from the endophytic fungus Penicillium brefeldianum and their cytotoxic activities, Chinese Chemical Letters, 28(6):1194-1199, https://doi.org/10.1016/j.cclet.2017.02.022

25. Grum D. S., Cook D., Baucom D., MottI. W., Gardner D. R., Creamer, R., \& Allen, J. G. (2013). Production of the alkaloid Swainsonine by a fungal endophyte in the host Swainsona canescens, J.Nat.Prod.,76(10): 1984-1988, https://doi.org/10.1021/np400274n

26. Harwoko, H., Lee, J., Hartmann, R., Mándi, A., Kurtán, T., Müller, W.E.G., Feldbrügge, M., Kalscheuer, R., Ancheeva, E., Daletos, G., Frank, M., Liu, Z., Proksch, P. (2020). Azacoccones F $\mathrm{H}$, new flavipin - derived alkaloids from an endophytic fungus Epicoccum nigrum MK214079.Fitoterapia146: 104698https://doi.org/10.1016/j.fitote.2020.104698

27. Hawary - El. S. S., Moawad. A. S., Bahr. H. S., Abdelmohsen U. R., \& Mohammed. R. (2020). Natural product diversity from the endophytic fungi of the genus Aspergillus. RSC Adv, 10(37); 22058-22079, https://doi.org/10.1039/D0RA04290K

28. He. J, Lion. U., Sattler. I., Gollmick F. A., Grabley. S., Cai. J., Meiners. M., Schunke. H, Schaumann. K, Dechert. U., \& Krohn. M. (2005). Diastereomeric Quinolinone alkaloids from the marine derived fungus Penicillium Janczewskii, J. Nat. Prod, 68(9); 1397 - 1399, https://doi.org/10.1021/np058018g

29. Hulvova H., Gluszka, P., Frebortova, J., \& Frebort, I. (2012). Parasitic fungus Claviceps as a source for biotechnological production of ergot alkaloids. Biotechnology Advances, 31(1): 79-89, https://doi.org/10.1016/j.biotechadv.2012.01.005

30. Ibrahim. S. R. M., Mohamed. G. A., Moharram. A. M, Diaa T. A., \& Youssef. D. T. A. (2015). Aegyptolidines A and B: New pyrrolidine alkaloids from the fungus Aspergillusaegyptiacus. Phytochemistry Letters. 12 : 90 - 93, https://doi.org/10.1016/j.phytol.2015.03.001

31. Isaka. M., Rugseree. N., Maithip. P., Kongsaeree. P., Prabpai. S., \& Thebtaranonth. Y. (2005). Hirsutellones A- E, antimycobacterial alkaloids from the insect pathogenic fungus Hirsutella nivea BCC2594. Tetrahedron., 61(23):5577-5583, https://doi.org/10.1016/j.tet.2005.03.099 
Archana O \& Praveen Kumar Nagadesi; Saudi J Pathol Microbiol, Jan, 2022; 7(1): 4-19

32. Jiang, C.S, Zhou, Z.F., Yang X.H., Lan L. F., Gu Y.C., Ye B.P., \& Guo, Y.W. (2018). Antibacterial sorbicillin and diketopiperazines from the endogenous fungus Penicillium sp. GD6 associated Chinese mangrove Bruguiera gymnorrhiza, Chinese Journal of Natural Medicines, 16(5); 358 365, https://doi.org/10.1016/S18755364(18)30068-2

33. Kanokmedhakul. K., Kanokmedhakul. S., Suwannatrai. R., Soytong. K., Prabpai. S., \& Kongsaeree. P. (2011). Bioactive meroterpenoids and alkaloids from the fungus Eurotium chevalieri. Tetrahedron, 67(30); 5461-5468, https://doi.org/10.1016/j.tet.2011.05.066

34. KatoH., Yoshida T., Tokue T., Nojiri Y., Hirota H., Ohta T., Williams R. M., Tsukamoto S. (2007). Notoamides A-D: prenylated indole alkaloids isolated from a marine - derived fungus, Aspergillus sp., Angew. Chem. Int. Ed. Engl, 46(13):2254-2256, https://doi.org/10.1002/anie.200604381

35. Kato. Y., Koshino. H., Uzawa, J., \& Anzai. K. (1996). Fungerin, a new antifungal alkaloid from Fusarium sp. (1996). Bioscience, Biotechnology, and Biochemistry, 60(12):; 2081 - 2083, https://doi.org/10.1271/bbb.60.2081

36. Kim, J. Y., Ki., D. W., Lee, Y. J., Ha, L. S., Woo, E. E., Lee, I. K., \& Yun, B. S. (2021). Consoramides A - C, New zwitterionic alkaloids from the fungus Irpex consors, Mycobiology, 49(4); $\quad 434 \quad-437$, https://doi.org/10.1080/12298093.2021.1924926

37. Koolen, H. H. F., Soares E. R., Dasilva F. M. A., Dealmeida R. A., DesouzaA. D. L., DemedeirosL. S., Filho E. R., Desouza A. Q. L. (2012). An antimicrobial alkaloid and other metabolites produced by Penicillium sp. An endophytic fungus isolated from Mauritia flexuosa L.f. Quim. Nova, 35(4); 771-774, https://doi.org/10.1590/S010040422012000400022

38. Kuklev,, D.V., \& Dembitsky, V.M. (2016). Chemistry, origin, antitumor and other activities of fungal homo - dimeric alkaloids, M J Phar, 1(1); 004, ISSN 2474 - 753X

39. Kumara. A., Patil, Deepak., Rajamohanan. P. R., \& Ahmad. A. (2013). Isolation, purification and characterization of vinblastine from endophytic fungus Fusarium oxysporum isolated from Catharanthus roseus. PLos One. 16; 8(9):e71805. https://doi.org/10.1371/journal.pone.0071805

40. Kumara. P. M., Soujanya, K. N., Ravikanth. G., Vasudeva, R., Ganeshaiah, K.N., \& Shaankar. R. U. (2014). Rohitukine, a chromone alkaloid and a precursor of flavopiridol,is produced by endophytic fungi isolated from Dysoxylum binectariferumHook.f and Amoora rohituka (Roxb).Wight and Arn, Phytomedicine, 21(4); 5416,https://doi.org/10.1016/j.phymed.2013.09.019
41. Kumarihamy. M., Fronzczek, F. R, DFerriera. Jacob. M, Khan. S. I., Nanayakkara. N.P.D. (2010). Bioactive 1, 4-dihydroxy - 5 - phenyl - 2 pyridinone alkaloids from Septoria pistaciarium, J. Nat. Prod., 73(7):1250 - 1253, https://doi.org/10.1021/np1000939

42. Lee, C., Sohn, J. H., Jang, J.H., Ahn, J. S., H. O.H., J. Baltrusaitis. (2015). Cyclopansamines A., \& B: Spiroindolinone alkaloids from a marine isolate of penicillium sp. ( $\mathrm{SF}$ - 5292). The Journal of Antibiotics, $\quad 68 ; \quad 715-718$ https://doi.org/10.1038/ja.2015.56

43. Li, D., Li X. M., Li, T. G., Dang, H.Y., Proksch, P., \& Wang, B.G. (2008). Benzaldehyde derivatives from Eurotium rubrum, an endophytic fungus derived from the mangrove plant Hibiscus tiliaceus" Chem Pharm Bull (Tokyo) 56(9); 1282 1285, https://doi.org/10.1248/cpb.56.1282

44. Li, H., Sun, W., Deng, M., Zhou, Q., Wang, J., Liu, J., Chen, C., Qi, C., Luo,, Z., Xue, Y., Zhu, H., \& Zhang, Y. (2018). Asperversiamides, linearly fused prenylated indole alkaloids from the marine derived fungus Aspergillus versicolor. J. Org. Chem., 83(15); 8483-8492, https://doi.org/10.1021/acs.joc.8b01087

45. Li, L. Y., Ding. Y., Groth. I., Menzel. K. D., Peschel, G., Voigt, K., Deng. Z. W., Sattler., I., \& Lin. W.H. (2008). Pyrrole and indole alkaloids from an endophytic Fusarium incarnatum (HKI00504) isolated from the mangrove plant Aegiceras corniculatum, Journal of Asian Natural Produts Research, 10(8); 765770,https://doi.org/10.1080/10286020802031106

46. Li, X.B., Li. L., Zhu. R. X., Li. W, Chang. W. Q., Zhang. L.L., Wang. X. N., Zhao. Z. T., and Lou. H. X. (2015). Tetramic acids and pyridine alkaloids from the endolichenic fungus Tolypocladium cylindrosporum, J. Nat. Prod., 78(9); 2155-2160, https://doi.org/10.1021/np501018w

47. Li. X, Kim. S. K., Nam. K. W., Kang. J. S., Choi. H. D., \& Byeng Wha Son. B. W. (2006). A new antibacterial dioxopiperazine alkaloid related to Gliotoxin from a marine isolate of the fungus Psudallescheria. J Antibiot, 59(4); 248-250, https://doi.org/10.10.38/ja.2006.35

48. Li, Y., Li, X., Kim. S.K., Kang, J. S., Choi. H. D., Rho, J. R., \& Son. B. W. (2004).Golmaenone, a new diketopiperazine alkaloid from the Marine derived fungus Aspergillus sp. Chem Pharm Bull, 52(5); $\quad 375 \quad-\quad 376$, https://doi.org/10.1248/cpb.52.375

49. Limbadri. S., Luo. X., Lin. X., Liao. S., Wang. J., Zhou. X., Yang. B and Liu. Y. (2018). Bioactive novel indole alkaloids and steroids from deep sea derived fungus Aspergillus fumigatus SCSIO 41012.Molecules, 23(9); 2379, https://doi.org/10.3390/molecules23092379

50. Lin. X, Ai. W., Li. M, Zhou. X., Liao. S., Wang. J., Liu. J., Yang. B., \& Liu, Y. (2020). 
Collacyclumines A-D from the endophytic fungus colletotrichum solsolae SCSIO41021 isolated from the mangrove kandelia candel. Phytochemistry. 171:112237, https://doi.org/10.1016/j.phytochem.2019.112237

51. Lin. Z., Wen. J., Zhu. T., Fang. Y., Gu, Q., \& Zhu, W. (2008). Chrysogenamide A from an endophytic fungus associated with Cistanche deserticola and its neuroprotective effect on SH-SY5Ycells, J. Antibiot 61(2): 81-85, https://doi.org/10.1038/ja.2008.114

52. Ma. Y. M., Qiao. K., Kong. Y., Li. M. Y., Guo. L. X., Miao, Z., \& Fan. C. (2017). Anew isoquinolone alkaloid from an endophytic fungus R22 of Nerium indicum. Nat Prod Res. 31(8);951-958, https://doi.org/10.1080/14786419.2016.1258556

53. Maehara. S., Simanjuntak, P., Kitamura. C., Ohashi, K., \& Shibuya. H. (2019). Cinchona alak.aoids are also produced by an endophytic filamentous fungus living in cinchona plant. Chem Pharm Bull, 59(8); 1073 - 4. https://doi.org/10.1007/s11418-018-1273-z

54. Metwaly, A. M., Ghoneim, M. M., \& Musa, A. (2015). Two new antileishmanial diketopiperazine alkaloids from the endophytic fungus Trichosporum species. Der Pharma Chemical, 7(11); 322-327

55. Na. R., Jiajia. L., Dongliang. Y., Yingzi. P., Juan. H., Xiong. L., Nana. Z., Jing. Z., \& Yitian. L. (2016). Identification of vincamine indole alkaloids producing endophytic fungi isolated from Nerium indicum, Apocynaceae. Microbiological Research. 192:114-121. https://doi.org/10.1016/j. micres.2016.06.008.

56. Omura., S., Hirano. A., Iwai, Y., \& Masuma. R. (1979). Herquline, a new alkaloid produced by Penicillum herquei fermentation, isolation and properties, J Antibiot, 32(8): 786-90, https://doi.org/10.7164/antibiotics.32.786

57. Ortega, H. E., Graupner P. R., Asai, Y., Tendyke, K., Qiu, D., Shen, Y. Y., Rios, N., Arnold, A. E., Coley, P. D., KursarT. A., Gerwick, W. H., \& RiosL. C. (2013). Mycoleptodiscins A and B, Cytotoxic alkaloids from the Endophytic fungus Mycoleptodiscus sp. F0194. J. Nat. Prod, 76(4); 741-744, https://doi.org/10.1021/np300792t

58. Osterhage, C., Kaminsky, R., Konig, G. M., \& Wright, A. D. (2000). Ascosalipyrrolidinone A, an antimicrobial Alkaloid, from the obligate Marine fungus Ascochyta salicorniae, J. Org. Chem, 65(20); $\quad 6412 \quad-6417$, https://doi.org/10.1021/jo000307g

59. Palem. P.P.C, Kuriakose. G. C., Jayabaskaran. C. (2015). An endophytic fungus, Talaromyces radicus, isolated from Catharanthus roseus, produces Vincricristine and Vinblastine, which induce Apoptotic cell death, PLo S ONE, 10(12); e0144476.,

https://doi.org/10.1371/journal.pone.0144476
60. Paluka, J., Kanokmedhakul, K., Soytong, M., Soytong, K., Yahuafai, J., \& Siripong, P., Kankmedhakul, S. (2020). Meroterpenoid Pyrones, alkaloid and bicyclic brasiliamide from the fungus Neosartorya hiratsukae, Fitoterapia, 142; 104485 , https://doi.org/10.1016/j.fitote.2020.104485

61. Pan, F., Hou, K, Gao, F., Hu, B., Chen, Q., \& Wu, W. (2014). Peimisine and peiminine production by endophytic fungus Fusarium sp. Isolated from Fritillariaunibracteata Phytomedicine, var.wabensis https://doi.org/10.1016/j.phymed. 2014.04.010

62. Pan, F., Su, X., Hu, B., Yang, N., Chen, Q., \& Wu, W. (2015). Fusarium redolens 6WBY3, an endophytic fungus isolated from Fritillaria unibracteata var.wabuensis, produces peimisine and imperialine $-3 \quad \beta \quad$-Dglucoside.Fitoterapia103:213-221, https://doi.org/10.1016/j.fitote.2015.04,006

63. Peng, F., Hou, S.Y., Zhang, T.Y., Wu, Y.Y., Zhang, M.Y., YanX.M., Xia, M.Y., \& Zhang, Y. $X$. (2019). Cytotoxic and antimicrobial indole alkaloids from an endophytic fungus Chaetomium sp. SYP-F7950 of Panax notoginseng. RSC Adv 9:28754-28763, https://doi.org/10.1039/C9RA047447F

64. Peng. J, Lin. T., Wang. W., Xin, Z., Zhu, T., Gu, Q., \& Li. D. (2013). Antiviral alkaloids produced by the mangrove derived fungus Cladosporium species. PJX - 41, J. Nat. Prod. 76(6):1133 - 1140, https://doi.org/10.1021/np400200k

65. Peng. J., Zhang, X.Y., Tu, Z.C., Xu, X.Y., \& Qi, S.H. (2013). Alkaloids from the deep - seaderived fungus Aspergillus westerdijkiae DFFSCS013, J. Nat. Prod, 76(5); 983 - 987, https://doi.org/10.1021/np400132m

66. Philippe, G.(2016). Lolitrem B and indole diterpene alkaloids produced by endophytic fungi of the genus Epichole and their toxiceffects in livestock" 8(2):47,https://doi.org/10.3390/toxins8020047

67. Pinheiro, E. A. A., Carvalho J.M.Dos Santos D. C. P., Feitosa A. O., Marinho, P. S. B., Guilhon, G. M. S. P., DesouzaA. D. L., Dasilva F. M. A., \&. Marinho, A. M. R (2013). Antibacterial activity of alkaloids produced by endophytic fungus Aspergillus sp. EJC08 isolated from medical plant Bauhinia guianensis, Natural Product Research, 27(18): 1633-1638, DOI: 10.1080/14786419.2012.750316

68. Porter, J. K., Bacon, C.W., Robbins, J.D., Himmelsbach, D. S., \& Higman, H.C. (1977). Indole alkaloids from Balansis epichole (Weese), $J$. Agric. Food Chem., 25(1); 88-93, https://doi.org/10.1021/jf60209a043

69. Pund. S., \& Joshi. A. (2017). Nano - and microscale drug delivery systems. https://doi.org/10.1016/B978-0-323-527279.00023-6 
Archana O \& Praveen Kumar Nagadesi; Saudi J Pathol Microbiol, Jan, 2022; 7(1): 4-19

70. Quang, D. N., Schmidt, J., \& Porzel, A. (2010). Ampullosine, a new isoquinoline alkaloid from Sepedonium ampullosporum (Ascomycetes), Natural Product Communications, 5(6); 869 872.https://doi.org/10.1177/1934578X1000500609

71. Rahbaek, L, Breinholt. J., Frisvad, J. C., \& Christophersen, C. (1999). Circumdatin A.B.C: Three new benzodiazepine alkaloids isolated from a culture of the fungus Aspergillus ochraceus, J.org. Chem, 64(5);1689-1692, https://doi.org/10.1021/jo981536u

72. Roy, A. (2017). A review on the alkaloids an important therapeutic compound from plants. International Journal of Plant Biotechnology, 3(2); $1-9$.

73. Schmidt, K., Riese. U, Li. Z., \& Hamburger. M. (2003). Novel Tetramic acids and pyridine alkaloids, militarinones B, C., \& D from the insect pathogenic fungus Paecilomyces militaris, J. Nat. prod, $66(3) ; \quad 378 \quad-\quad 383$, https://doi.org/10.1021/np020430y

74. Shan. W. G, Ying. Y. M, Yu. H. N., \& Liu. W. H. (2010). Diketopiperazine alkaloids from Penicillium sp. HS-3, an endophytic fungus in Huperzia serrata.Helvetica Chimica Acta. 93(4):772 - 776, https://doi.org/10.1002/hlca.200900331

75. Shweta. S., Gurumurthy. B. R., Ravikanth. G., Ramanan. U. S., \& Shivanna. M. R. (2012). Endophytic fungi from Miquelia dentate Bedd., produce the anti - cancer alkaloid, camptothecine. Phytomedicine, 15; 20(3-4):33742.https://doi.org/10.1016/j.phymed.2012.11.015

76. Singh. S. Singh. A., Jaiswal. J., Singh T. D., Singh V. P., Pandey. V.B., Tiwari. A., \& Singh. U. P. (2010). Antifungal activity of the mixture of quaternary alkaloids isolated from Argemone Mexicana against some phytopathogenic fungi. Archives of Phytopathology and Plant Protection, 43(8):769 774 https://doi.org/10.1080/03235400802176159

77. Smetanina. O.F, Kalinovsky A.I, Khudyakova Y. V., Pivkin M.V., Dmitrenok. P. S., Fedorov. S. N., Ji. H., Kwak. J. Y., \& Kuznetsova. T. A. (2007). Indole alkaloids produced by a marine fungus isolate of Penicillium janthinellum Biourge, J.Nat.Prod., 70(6):906-909, https://doi.org/10.1021/np060396d

78. Song. R, Wang. J, Sun. L., Zhang. Y, Ren. Z., Zhao. B, and Lu. H. (2019). The study of metabolites from fermentation culture of Alternariaoxytropis, BMC Microbiol. 19(1):35. https://doi.org/10.1186/s12866-019-1408-8

79. Spilsbury, J.F., \& Wilkinson, S. (1961). The isolation of festuclavine and two new clavinet alkaloids from Aspergillus fumigatusFres, J. Che. Soc., https://doi.org/10.1039/JR9610002085
80. Su. J and Yang. M. (2015). Huperzine A production by Paecilomyces tenuis YS-13, an endophytic fungus isolated from Huperzia serrata,Nat Prod Res., 29(11):103541,https://doi.org/10.1080/14786419.2014.980245

81. Sun, C., Ge, X., Mudassir, S., Zhou, L., Yu, G., Che, Q., Zhang, G., Peng, J., Gu, Q., Zhu T, Li, D. (2019). New glutamine containing Azaphilone alkaloids from deep sea derived fungus Chaetomium Globosum HDN151398, Mar Drugs. 17(5):253, https://doi.org/10.3390/md17050253

82. Sun, X. P., Xu. Y., Cao. F., Xu. R. F., Zhang. L. X., \& Wang. C. Y. (2014). Isoechinulin - type alkaloids from a soft coral derived fungus Nigrosporaoryzae. Chemistry of Natural Compounds, 50; $1153 \quad-\quad 1166$, https://doi.org/10.1007/s10600-014-1189-0

83. Supothina, S., Isaka, M., \& Wongsa, P. (2007). Optimization of culture conditions for production of the anti - tubercular alkaloid hirsutellone A by Trichoderma gelatinosum BCC7579. Lett Appl Microbiol., 44(5):531-537, https://doi.org/10.1111/j.1472-765X.2006.02089.x

84. Tsai H.F., Wang H., Gebler J.C., Poulter C.D., \& Schardl C.L.The Claviceps purpurea gene encoding dimethylallyltryptophan synthase, the committed step for ergot alkaloid. Biochem Biophys Res Commun., 216(1):119-125, https://doi.org/10.1006/bbrc.1995.2599

85. Tsuchinari, M., Shimanuki, K., Hiramatsu, F., Murayama, T., Koseki, T., \& Shiono. Y. (2007). Fusapyridons A and B, Novel Pyridone alkaloids from an endophytic fungus, Fusarium sp. YG- 45, Z.Naturforsch.62b:1203-1207, https://doi.org/10.1515/znb-2007-0916

86. Tsuda, M., Kasai. Y., Komatsu, K., Sone, T., Tanaka, M., Mikami, Y., \& Kobayashi, J. (2004). Citrinadin A, a novel pentacyclic alkaloid from marine - derived fungus Penicillium citrinum, Org.Lett.,6(18):3087-3089, https://doi.org/10.1021/oI048900y

87. Verma. V. C., Lobokovsky E., Gange. A. C., Singh. S. K., and Prakash. S. (2011). piperine production by endophytic fungus Perconia $\mathrm{sp}$. Isolated from Piperlongum L.,The journal of antibiotics. https://doi.org./10.1038/JA.2011.27

88. Wang, A., Zhao, S., Gu G., Xu D., Zhang X., Lai, D., \& Zhou, L. (2020). Rhizovagine A, an unusual dibenzo $-\alpha-$ pyrone alkaloid from the endophytic fungus Rhizopycnis vagum Nitaf22. RSC Adv., 10: 27894-27898, https://doi.org/10.1039/D0RA05022A

89. Wang, F., Fang Y., Zhu, T., Zhang, M., Lin A., Gu, Q., \& Zhu, W. (2008). Seven new prenylated indole diketopiperazine alkaloids from holothurian - derived fungus Aspergillus fumigatus. Tetrahedron64(34): $\quad$ 7986-7991, https://doi.org/10.1016/j.tet.2008.06.013 
Archana O \& Praveen Kumar Nagadesi; Saudi J Pathol Microbiol, Jan, 2022; 7(1): 4-19

90. Wang. J, Wei. X, Qin. X, Lin. X, Zhou. X, Liao. S, Yang. B, Liu. J, Tu. Z, Liu. Y.(2015). Arthpyrones A - C, pyridine alkaloids from a sponge - derived fungus Arthrinium arundinis ZSDS1 - F3. Org.Lett. $\quad 17(3): 656 \quad-\quad 659$, https://doi.org/10.1021/o1503646c

91. Wang. X. J., Min. C. L., Ge. M and Zuo. R. H. (2014). An endophytic Sanguinarine - producing fungus from Macleaya cordata, Fusarium proliferatum BLH51. Curr Microbiol. 68(3):336341), https://doi.org/10.1007/s00284-013-0482-7

92. WijeratneE. M. K., HeH., FranzblauS. G., Hoffman A. $\mathrm{M}$ and GunatilakaA. A L.(2013). Phomapyrrolidones A - C, antitubercular alkaloids from the endophytic fungus Phoma sp. NRRL 46751, J. Nat. Prod.76, (10): 1860 - 1865, https://doi.org/10.1021/np400391p.

93. Xin. Z. H., Fang. Y., Du. L., Zhu. T., Duan. L., Chen. J., Gu. Q.Q., Zhu. W.M. (2007). Aurantiomides A-C, Quinazoline alkaloids from the sponge - derived fungus Penicillium aurantiogriseum SP0-19. J.Nat.Prod.70(5): 853855, https://doi.org/10.1021/np060516h

94. XuG.B., HeG., BaiH.H., YangT., ZhangG.L., Wu L.W. and LiG.Y.(2015)Indole alkaloids from Chaetomium globosum, J. Nat. Prod. 78, (7):14791485, https://doi.org/10.1021/np5007235

95. Xu. D., Luo. M, Liu. F., Wang. D, Pang. X, Zhao. T, Xu. L, Wu. X, Xia. Mand Yang. X.(2017). Cytochalasan and tyrosine derived alkaloids from the marine sediment derived fungus Westerdykella dispersa and their bioactivities. Sci Rep 7:11956, https://doi.org/10.1038/s41598-017-12327-1

96. Xu. W. F., Mao. N., Xue. X. J, Qi. Y. X., Wei. M. Y., Wang. C. Y., \& Shao. C. L.(2019).Structures and Absolute configurations of Diketopiperazine of alkaloids Chrysopiperazines A - C from the Gorgonian - derived Penicillium Chrysogenum fungus. Mar. Drugs. 17(5):250, https://doi.org/10.3390/md17050250

97. Yang. S. X., Xiao. J., Holstein. L. J, Dittrich. B.,Zhang. Q., Gao. J. M. (2012).Fusarimine, a novel polyketide isoquinoline alkaloid, from the endophytic fungus Fusarium sp. LN12, isolated from Melia azedarach. Tetrahedron Letters.53(47):6372-6375, https://doi.org/10.1016/j.tetlet.2012.09.031

98. Yunianto, P., Rusman, Y., Saepudin, E., Suwarso, W. P., \& Sumaryono. W. (2014). Alkaloid (Meleagrine and Chrysogine) from endophytic fungi (Penicillium sp.) of Annona squamosa L., Pak J Biol Sci., 17(5):667-674, https://doi.org/10.3923/pjbs.2014.667.674

99. Zhang. P, Li. X. M, Liu. H, Li. X., \& Wang. B. G. (2015). Two new alkaloids from Penicillium oxalicum EN-201,an endophytic fungus derived from the marine mangrove plant Rhizophora stylosa, Phytochemistry Letters, 13:160-164, https://doi.org/10.1016/j.phytol.2015.06.009

100.Zhang. P, Yuan. X. L, Du. Y.M, Zhang. H. B, Shen. G.M, Zhang. Z. F, Liang. Y. J, Zhao. D. L and Xu. K. (2019). Angularly prenylated indole alkaloids with antimicrobial and insecticidal activities from an endophytic fungus Fusarium sambucinum TE - 6L, J Agric Food Chem., 67(43):11994 - 12001, https://doi.org/10.1021/acs.jafc.9b05827

101.Zhang. P., Li. X. M., Wang. J. N., \& Wang.B. G. (2015). Oxepine - containing diketopiperazine alkaloids from the algal derived endophytic fungus Paecilomyces variotii EN - 291, Helvetica Chimica Acta., 98(6):800-804, https://doi.org/10.1002/hlca.201400328

102.Zhang. Y., Han. T.,Ming. Q., Wu. L., Rahman. K and Qin. L. (2012). Alkaloids produced by endophytic Fungi. Nat Prod Commun. 7(7):963968,https://doi.org/10.1177/1934578X1200742

103.Zheng C.J., Li L., Zou J.P., Han T., Qin L. P. (2011).Identification of a quinazoline alkaloid produced by Penicillium vinaceum, an endophytic fungus from Crocus sativus. Pharmaceutical Biology 50(2): 129 - 133, https://doi.org/10.3109/ 13880209. 2011.569726

104.Zhong. W. M., Wang. J. F., Shi. X. F., Wei. X. Y., Chen. Y. C., Zeng. Q., Xiang. Y., Chen. X.Y., Tian. X. P., Xiao. Z. H., Zhang. W. M., Wang. F. Z., \& Zhang. S.(2018). Eurotiumins A - E, five new alkaloids from the marine derived fungus Eurotium sp. SCSIO F452.MarDrugs.16(4):136, https://doi.org/10.3390/md16040136

105.Zhu. M, Zhang. X, Feng. H and Che. Q. (2016). Campyridones A-D, pyridone alkaloids from a mangrove endophytic fungus Campylocarpon sp. HDN13-307, Tetrahedron, 72(37):56795683,https://doi.org/10.1016/j.tet.2016.07.080

106.Zhu. M, Zhang. X, Feng. H, Dai. J, Li. J, Che. Q, Gu. Q, Zhu. T and Li. D. (2016).Penicisulfuranols A - F, alkaloids from the mangrove endophytic fungus Penicillium janthinellum HDN13 - 309,J. $\begin{array}{lll}\text { Nat. } & \text { Prod. } & \text { 80(1):71-75, }\end{array}$ https://doi.org/10.1021/acs.jnatprod.6b00483

107.Zou. R., wei. C, Xuexia Zhang. X., Zhou. D., and $\mathrm{Xu}$. J. (2021).Alkaloids from endophytic fungus Aspergillus fumigatus HQD24 isolated from the Chinese mangrove plant Rhizophora mucronate. Nat Prod Res. 15.https://doi.org/10.1080/14786419.2021.1916017

108.Zou. X., Liu. S., Zheng. Z., Zhang. H., Chen. X., Liu. X., \& Li. E. (2011). Two new imidazolone containing alkaloids and further metabolites from the ascomycete fungus Tricladium sp. Chem Biodivers. $\quad 8(10): 1914 \quad-\quad$ 1920, https://doi.org/10.1002/cbdv.201000372 